\title{
Large Faraday effect and structural properties of heavily Tb3+-doped borogermanate glasses: a potential precursor of magneto-optical fibers
}

Douglas Franco

Sao Paulo State University

Yannick Ledemi

Université Laval

Wagner Correr

Université Laval

Steeve Morency

Université Laval

Conrado Afonso

Federal University of São Carlos

Sandra Helena Messaddeq

Université Laval

Younès Messaddeq

Université Laval

Marcelo Nalin ( $\triangle$ marcelo.nalin@unesp.br)

Sao Paulo State University

\section{Research Article}

Keywords: Faraday effect, magneto-optical (MO) fibers, glass

Posted Date: February 24th, 2021

DOI: https://doi.org/10.21203/rs.3.rs-235342/v1

License: (c) (1) This work is licensed under a Creative Commons Attribution 4.0 International License. Read Full License 


\section{Large Faraday effect and structural properties of heavily $\mathbf{T b}^{3+}$-doped}

borogermanate glasses: a potential precursor of magneto-optical fibers

Douglas F. Franco ${ }^{1 *}$, Yannick Ledemi ${ }^{2}$, Wagner Correr ${ }^{2}$, Steeve Morency $^{2}$, Conrado R. M. Afonso ${ }^{3}$, Sandra H. Messaddeq ${ }^{2}$, Younès Messaddeq ${ }^{1,2}$ and Marcelo Nalin $^{1 *}$

${ }^{1}$ Institute of Chemistry, State University of São Paulo (UNESP), Araraquara, SP, 14800-060, Brazil

${ }^{2}$ Centre d'Optique, Photonique et Laser, Université Laval, 2375 rue la Terrasse, local 2131, Quebec (Qc), GIV 0A6, Canada

${ }^{3}$ Department of Materials Engineering (DEMa), Federal University of São Carlos (UFSCar), São Carlos, SP, Brazil

* Corresponding authors:

dffrancopdoctor@outlook.com

marcelo.nalin@unesp.br 


\section{Abstract}

New glass compositions containing high concentrations of $\mathrm{Tb}^{3+}$ ions were developed aiming at the production of magneto-optical (MO) fibers. This work reports on the structural and MO properties of a new glass composition based on $(100-x)\left(41 \mathrm{GeO}_{2}\right.$ $\left.25 \mathrm{~B}_{2} \mathrm{O}_{3}-4 \mathrm{Al}_{2} \mathrm{O}_{3}-10 \mathrm{Na}_{2} \mathrm{O}-20 \mathrm{BaO}\right)-x \mathrm{~Tb}_{4} \mathrm{O}_{7}$. Morphological analysis (HR-TEM) of the sample with the highest concentration of $\mathbf{T b}^{3+}$ ions confirmed the homogeneous distribution of $\mathrm{Tb}^{3+}$ ions and the absence of nanoclusters. All the samples presented excellent thermal stability against crystallization $\left(\Delta T>100{ }^{\circ} \mathrm{C}\right)$. An optical fiber was manufactured by a fiber drawing process. The UV-Vis spectra of the glasses showed $\mathrm{Tb}^{3+}$ electronic transitions and optical windows varying from 0.4 to $1.6 \mu \mathrm{m}$. The magnetooptical properties and the paramagnetic behaviors of the glasses were investigated using Faraday rotation experiments. The Verdet constant $\left(V_{B}\right)$ values were calculated at 500 , $650,880,1050,1330$, and $1550 \mathrm{~nm}$. The maximum $V_{B}$ values obtained at 650 and $1550 \mathrm{~nm}$ for the glass with $x=18 \mathrm{~mol} \%$ were -128 and $-17.6 \operatorname{rad~T}^{-1} \mathrm{~m}^{-1}$, respectively. The $V_{B}$ values at 500 and $1550 \mathrm{~nm}$ for the optical fiber containing $8 \mathrm{~mol} \%$ of $\mathrm{Tb}_{4} \mathrm{O}_{7}$ were -110.2 and $9.5 \operatorname{rad~} T^{-1} \mathrm{~m}^{-1}$, respectively, while the optical loss at around $880 \mathrm{~nm}$ was $6.4 \mathrm{~dB} \mathrm{~m}^{-1}$.

\section{Introduction}

Magneto-optical (MO) materials based on the Faraday effect have been increasingly studied for use in new technologies ${ }^{1,2}$. MO materials have been applied as modulators, as optical isolators, and as magneto-optical fiber sensors ${ }^{3-5}$. A wide variety of transparent MO glasses, crystals, and transparent glass-ceramics containing rare earth (RE) ions such as $\mathrm{Tb}^{3+}, \mathrm{Dy}^{3+}$, $\mathrm{Pr}^{3+}$, and $\mathrm{Gd}^{3+}$ have been investigated and are considered promising materials for photonics and spintronics ${ }^{6-8}$.

The Faraday effect is defined by the rotation angle $(\theta)$ of a linearly polarized light beam, when the light travels through an optical path of known length (1), under the application of a longitudinal magnetic field (B) along the light propagation direction ${ }^{9}$. The MO performance of a material is evaluated and quantified by the magnitude of the Verdet constant $\left(V_{B}\right)$ value, and it may be maximized by the incorporation of paramagnetic species ${ }^{10}$.

Single crystals have larger $\mathrm{V}_{\mathrm{B}}$ values than magneto-optical glasses with similar composition. However, MO materials produced from glasses are more attractive than crystals, due to their lower cost, isotropy, and simple preparation procedures, in addition to great flexibility in obtaining materials with different shapes and lengths, such as fibers for applications in integrated devices ${ }^{11}$. Among the MO materials, especially attractive are 
paramagnetic glasses containing high concentrations of $\mathrm{Tb}^{3+}$ ions and with large $\mathrm{V}_{\mathrm{B}}$ values in UV-Vis-NIR regions ${ }^{12,13}$.

The development of MO glass compositions able to support high RE ions contents and with high thermal stability represents an important step towards achieving successful fiber drawing processes without crystallization. Studies have reported the production of MO fibers based on $\operatorname{Pr}^{3+}$-doped aluminosilicate ${ }^{14}$, Eu-doped silica glass ${ }^{15}, \mathrm{Gd}_{2} \mathrm{O}_{3}$ NPs-doped aluminosilicate glass ${ }^{16}$, and $\mathrm{Tb}^{3+}$-doped silicate glasses ${ }^{17}$.

The main prerequisites in selection of a good candidate glass material for MO applications are large $\mathrm{V}_{\mathrm{B}}$ values and transparency in the visible and near-infrared (NIR) regions. In particular, for the NIR region (at $1550 \mathrm{~nm}$ ), MO materials are good options for applications in telecommunication systems. Among all the paramagnetic ions, $\mathrm{Tb}^{3+}$ is one of the most attractive $e^{1,13,18}$. It has the electronic configuration $4 \mathrm{f}^{8} \rightarrow 4 \mathrm{f}^{7} 5 \mathrm{~d}^{8,9}$, providing good paramagnetic behavior and among the highest magnetic moments $\left(\mu_{\text {eff }}=9.5-9.72\right)$ and susceptibilities $(J=6$, $\mathrm{g}=1.46)$ of all the rare earth ions ${ }^{1}$. Additionally, terbium gallium garnet single crystals $\left(\mathrm{Tb}_{3} \mathrm{Ga}_{5} \mathrm{O}_{12}\right)$, known as TGG, are available commercially and are considered one of the most important bulk MO materials, with $\mathrm{V}_{\text {в }}$ of $-134 \mathrm{rad} \mathrm{T}^{-1} \mathrm{~m}^{-1}$ at $632 \mathrm{~nm}^{19}$.

Currently, heavy metal oxide (HMO) glasses based on borogermanates and borate glasses containing high $\mathrm{Tb}^{3+}$ ions contents stand out, due to their large $\mathrm{V}_{\mathrm{B}}$ values in the red region of the visible spectrum ${ }^{13}$. Gao et al. ${ }^{1}$ reported the MO properties of heavily $\mathrm{Tb}^{3+}$-doped materials with large Verdet constant values for use in fiber-integrated magneto-optics. In this case, the highest $\mathrm{V}_{\mathrm{B}}$ (at $632.8 \mathrm{~nm}$ ) was $-119 \mathrm{rad} \mathrm{T}^{-1} \mathrm{~m}^{-1}$ for glass containing $25 \mathrm{~mol} \%$ of $\mathrm{Tb}_{2} \mathrm{O}_{3}$. Franco et al. $^{20}$ reported $\mathrm{MO}$ glasses based on the $\mathrm{GeO}_{2}-\mathrm{B}_{2} \mathrm{O}_{3}-\mathrm{Al}_{2} \mathrm{O}_{3}-\mathrm{Na} 2 \mathrm{O}-\mathrm{PbO}-\mathrm{Tb}_{4} \mathrm{O}_{7}$ composition, with maximum $V_{B}$ values at 650 and $1550 \mathrm{~nm}$ equal to -83.9 and $-15.5 \mathrm{rad} \mathrm{T}^{-1} \mathrm{~m}^{-}$ ${ }^{1}$, respectively, for a sample containing $8 \mathrm{~mol} \%$ of $\mathrm{Tb}_{4} \mathrm{O}_{7}$ (35 wt\% of Tb dopant). In addition, the authors showed the production of an MO fiber from the drawing process of a glass containing $4 \mathrm{~mol} \%$ of $\mathrm{Tb}_{4} \mathrm{O}_{7}$. Yin et al. ${ }^{13}$ reported the structural and MO properties of $20 \mathrm{~Tb}_{2} \mathrm{O}_{3}-$ $20 \mathrm{Ga}_{2} \mathrm{O}_{3}-x \mathrm{~B}_{2} \mathrm{O}_{3}-(35-x) \mathrm{SiO}_{2}-20 \mathrm{GeO}_{2}(20 \leq x \leq 35)$ glasses. In this case, the authors reported the variation of $\mathrm{V}_{\mathrm{B}}$ values at $450 \mathrm{~nm}$ (from -210 to $-236 \mathrm{rad} \mathrm{T}^{-1} \mathrm{~m}^{-1}$ ), as a function of $\mathrm{B}_{2} \mathrm{O}_{3}$ content. Guo et al. ${ }^{21}$ showed that the $\mathrm{V}_{\mathrm{B}}$ values (at $632.8 \mathrm{~nm}$ ) of $\mathrm{GeO}_{2}-\mathrm{B}_{2} \mathrm{O}_{3}-\mathrm{SiO}_{2}-\mathrm{Ga}_{2} \mathrm{O}_{3}-x \mathrm{~Tb}_{2} \mathrm{O}_{3}(15 \leq$ $x \leq 30$ ) glasses ranged from -49.98 to $-120.54 \mathrm{rad} \mathrm{T}^{-1} \mathrm{~m}^{-1}$, with increase of the $\mathrm{Tb}_{2} \mathrm{O}_{3}$ content. Suzuki et al. ${ }^{12}$ reported large Faraday effects in bulk borate glasses containing $\mathrm{Tb}_{4} \mathrm{O}_{7}(45,55$, and $60 \mathrm{~mol} \%$ ). The large Verdet constant values for these $\mathrm{Tb}^{3+}$-borate glasses (at $633 \mathrm{~nm}$ ) were $-172,-212$, and $-234 \mathrm{rad} \mathrm{T}^{-1} \mathrm{~m}^{-1}$, respectively ${ }^{12}$. Savinkov et al. ${ }^{22}$ described the MO properties of transparent and colorless $\mathrm{Tb}_{2} \mathrm{O}_{3}-\mathrm{B}_{2} \mathrm{O}_{3}-\mathrm{GeO}_{2}$ (TBG) glasses containing up to $33 \mathrm{~mol} \%$ (or 
$12.13 \times 10^{-21}$ ion $\mathrm{cm}^{-3}$ ) of $\mathrm{Tb}_{2} \mathrm{O}_{3}$. The maximum $\mathrm{V}_{\mathrm{B}}$ value obtained at $632.8 \mathrm{~nm}$ was -0.409 arc $\min \mathrm{cm}^{-1} \mathrm{Oe}^{-1}\left(\sim-119 \mathrm{rad} \mathrm{T}^{-1} \mathrm{~m}^{-1}\right)$. As mentioned above, the literature includes very interesting works concerning MO characterization of bulk HMO glasses containing RE oxides, but very few papers have addressed MO fiber production ${ }^{17,20,23,24}$.

This work reports the synthesis and characterization of a new set of magneto-optical glasses based on $\mathrm{Tb}^{3+}$-containing borogermanate glass compositions. The thermal, structural, morphological, spectroscopic, and optical properties were investigated using differential scanning calorimetry (DSC), X-ray powder diffraction (XRD), high-resolution transmission electron microscopy (HRTEM), and Raman, UV-Vis-NIR, luminescence, and M-Lines spectroscopy methods. The magneto-optical properties were evaluated by Faraday rotation, with Verdet constant $\left(\mathrm{V}_{\mathrm{B}}\right)$ values measured at different wavelengths in the Vis-NIR range. In addition, a magneto-optical fiber was produced and characterized.

\section{Results and discussion}

Thermal, structural, and morphological analysis. Figure 1 shows the color evolution of the BGB- $x \mathrm{~Tb}$ glasses, as a function of the $\mathrm{Tb}^{3+}$ content. The same color change has been reported for calcium aluminosilicate and borogermanate glasses containing high $\mathrm{Tb}^{3+}$ contents, with the effects being attributed to the $\mathrm{Tb}^{3+}-\mathrm{Tb}^{4+}$ redox process and the conditions of melting ${ }^{1,22}$.

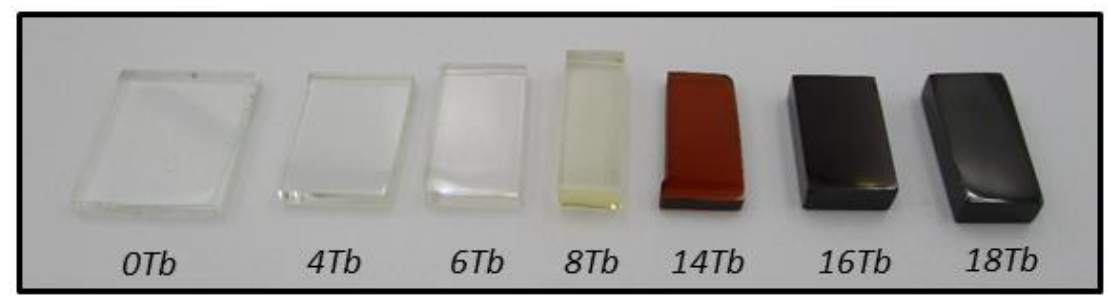

Figure 1. Photograph of BGB- $x \mathrm{~Tb}$ glasses with different $\mathrm{Tb}_{4} \mathrm{O}_{7}$ contents.

Figure 2(a) shows the DSC curves for all the BGB- $x$ Tb glasses. The characteristic temperatures of glasses, including the glass transition $\left(\mathrm{T}_{\mathrm{g}}\right)$, onset of crystallization $\left(\mathrm{T}_{\mathrm{x}}\right)$, and maximum crystallization $\left(T_{p}\right)$, together with the thermal stability parameters $\left(\Delta T=T_{x}-T_{g}\right)$, were calculated for all the BGB- $x$ Tb samples. Table 1 summarizes the values of $T_{g}, T_{x}, T_{p}$, and $\Delta \mathrm{T}$, together with the density $\left(\mathrm{g} \mathrm{cm}^{-3}\right)$ and $\mathrm{Tb}^{3+}$ ions density (ions $\mathrm{cm}^{-3}$ ) values. The $\mathrm{Tb}^{3+}$ ions density was calculated using Equation 1: 


$$
N_{T b^{3+}}\left(\text { ions } \mathrm{cm}^{-3}\right)=\frac{4 x \rho N_{A}}{M}
$$

where, $N_{T b^{3+}}$ is the density of $\mathrm{Tb}^{3+}$ ions, $x$ is the mole fraction of $\mathrm{Tb}_{4} \mathrm{O}_{7}, N_{A}$ is the Avogadro constant, and $M$ is the average molecular weight of the BGB- $x$ Tb composition.
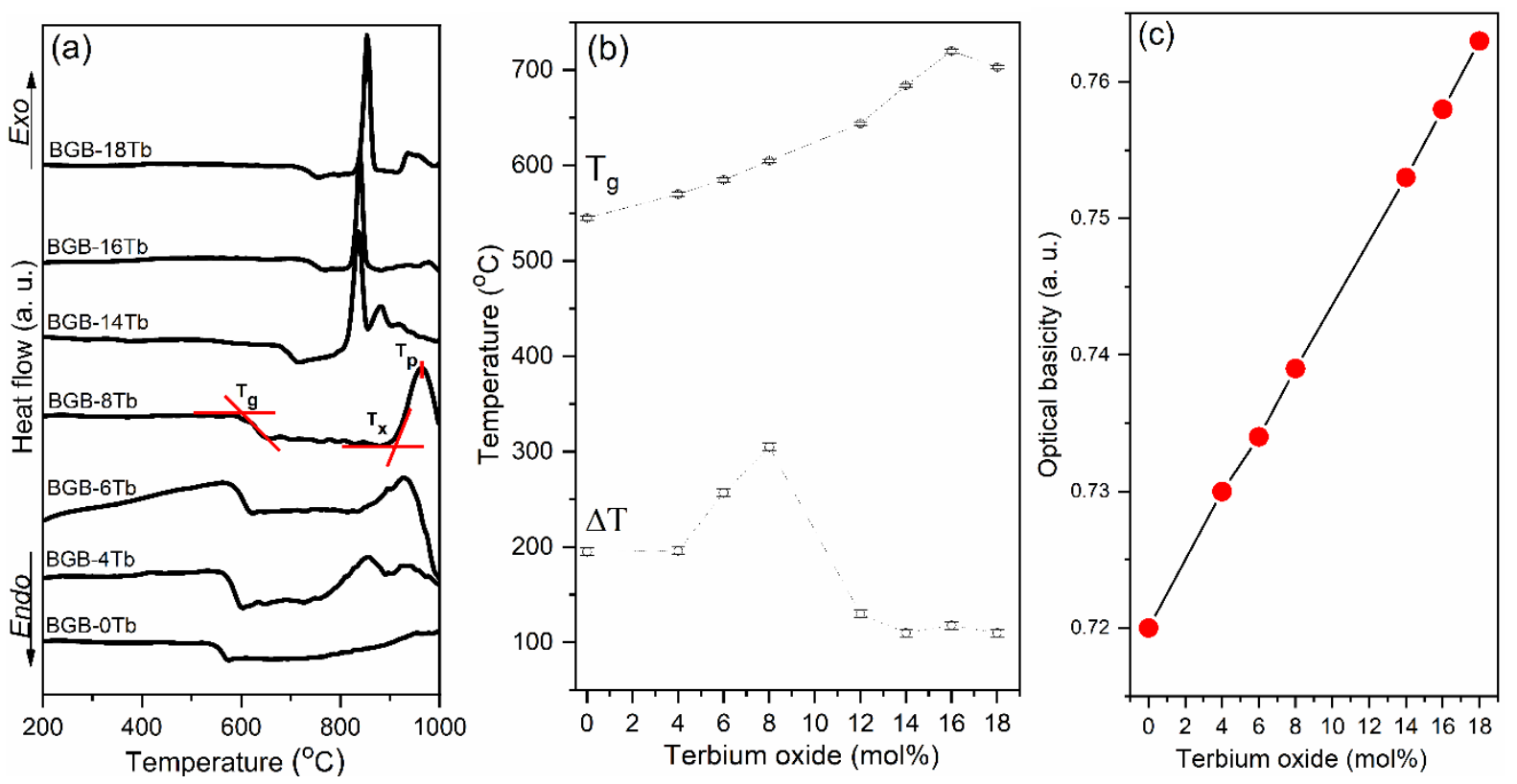

Figure 2. (a) DSC curves, (b) $\mathrm{T}_{\mathrm{g}}$ and $\Delta \mathrm{T}$, and (c) optical basicity, as a function of $\mathrm{Tb}_{4} \mathrm{O}_{7}$ concentration. The lines in (b) and (c) are just guides for the eyes.

\begin{tabular}{|c|c|c|c|c|c|}
\hline Sample label & $\mathrm{T}_{\mathrm{g}}$ & $\mathrm{T}_{\mathrm{x}}$ & $\Delta \mathrm{T}$ & $\rho\left( \pm 0.002 \mathrm{~g} \mathrm{~cm}^{-3}\right)$ & $\mathrm{NTb}^{3+}\left(10^{23} \mathrm{ins} \mathrm{cm}^{-3}\right)$ \\
\hline BGB-0Tb & 545 & 740 & 195 & 3.449 & 0 \\
\hline BGB-4Tb & 570 & 766 & 196 & 4.504 & 20.0 \\
\hline BGB-6Tb & 585 & 842 & 257 & 4.766 & 26.2 \\
\hline BGB-8Tb & 605 & 910 & 305 & 5.035 & 31.1 \\
\hline BGB-14Tb & 684 & 814 & 130 & 5.722 & 39.2 \\
\hline BGB-16Tb & 720 & 820 & 100 & 5.984 & 41.2 \\
\hline BGB-18Tb & 703 & 837 & 118 & 6.119 & 42.0 \\
\hline
\end{tabular}

Table 1. Glass transition temperature $\left(T_{g}\right)$, crystallization onset temperature $\left(T_{x}\right)$, maximum crystallization temperature $\left(\mathrm{T}_{\mathrm{p}}\right)$, thermal stability parameter $(\Delta \mathrm{T})$, density $(\rho)$, and $\mathrm{Tb}^{3+}$ ion density values for the BGB- $x \mathrm{~Tb}$ glasses. 
As can be seen in Figure $2 \mathrm{~b}$, the $\mathrm{T}_{\mathrm{g}}$ values increased as a function of the $\mathrm{Tb}^{3+}$ content, ranging from $545^{\circ} \mathrm{C}$ (BGB-4Tb) to $720^{\circ} \mathrm{C}$ (BGB-16Tb), followed by a decrease for the most concentrated sample, suggesting the occurrence of structural changes. It has been shown that in borogermanate glasses, RE ions may act as glass modifiers by breaking Ge-O-Ge bonds and inducing the formation of boroxol rings ${ }^{8,25}$. However, for the highest RE content, the structural connectivity was lost, resulting in a decrease of $\mathrm{T}_{\mathrm{g}}$. The BGB- $x \mathrm{~Tb}$ glasses presented high $\Delta \mathrm{T}$ values, with a maximum of $305{ }^{\circ} \mathrm{C}$ for the $\mathrm{BGB}-8 \mathrm{~Tb}$ sample, so this sample was the one selected for fiber production.

The optical basicity concept is based on the nature of the chemical bonding, according to Lewis acid-base theory and electronic polarization ${ }^{26,27}$. Duffy ${ }^{26,27}$ proposed an expression (Equation 2) based on optical basicity theory to calculate the average donor power of different constituents of a medium such as a multi-component oxide glass, since $\Lambda_{\text {th }}$ is related to the physical and chemical properties of glasses, including their structures and Verdet constants ${ }^{13}$ :

$$
\Lambda_{t h}=\Sigma x_{i} \cdot \Lambda_{i}
$$

where, $x_{i}$ is the mole fraction for one of the glass precursors $(i)$ and $\Lambda_{i}$ is the theoretical optical basicity value of an individual glass precursor. The intrinsic optical basicities of $\mathrm{GeO}_{2}, \mathrm{~B}_{2} \mathrm{O}_{3}$, $\mathrm{Al}_{2} \mathrm{O}_{3}, \mathrm{Na}_{2} \mathrm{O}, \mathrm{BaO}$, and $\mathrm{Tb}_{2} \mathrm{O}_{3}$ are $0.600,0.420,0.600,1.15,1.15$, and 0.954 , respectively ${ }^{27}$.

Qualitatively, $\Lambda_{\text {th }}$ is related to the electron donor power in a glass. In structural terms, the $\Lambda_{\text {th }}$ values assist in understanding the increase or decrease of non-bridge oxygen (NBO) (negatively charged) generated by a modifier agent in the glass ${ }^{13}$. According to Liu et al ${ }^{28}$ and Duffy $^{27}$, a lower value of $\Lambda_{\text {th }}$ reflects a lower content of NBO, so lower oxidation numbers of positively charged cations in the glass composition are consequently preferred.

As shown in Figure $2(\mathrm{c})$, the $\Lambda_{\text {th }}$ values increased as a function of the $\mathrm{Tb}_{4} \mathrm{O}_{7}$ content. This increase of $\Lambda_{\text {th }}$ could be explained by the greater polarizability of the glasses after the addition of $\mathrm{Tb}_{4} \mathrm{O}_{7}$, as well as the modifier action of $\mathrm{Tb}^{3+}$ ions in the glass network, which contributed to increasing the NBO bonds from the depolymerization of the germanate chains of the glass. Further evidence of NBO bonds in the BGB- $x$ Tb glass will be discussed in the Raman spectroscopy section. The $\Lambda_{\text {th }}$ values ranged from 0.720 (0Tb glass) to 0.763 (18Tb glass), with increase of $\mathrm{Tb}_{4} \mathrm{O}_{7}$. As reported by Yin et al. ${ }^{13}$ and Sontakke et al. ${ }^{29}$, high glass optical basicity is one of the factors contributing to the oxidation of $\mathrm{Tb}^{3+}$ to $\mathrm{Tb}^{4+}$ during the melting process, responsible for the red shift of the cutoff wavelength. Furthermore, it has been suggested that the addition of high concentrations of $\mathrm{Tb}_{4} \mathrm{O}_{7}$ may influence the modifier action of the glassy network constituted by Ge-O-Ge and B-O-B bridging bonds (BO), due to the fact 
that the $\mathrm{Tb}_{4} \mathrm{O}_{7}$ structure contains voluminous polyhedrons larger than those formed by $\mathrm{GeO}_{2}$ and $\mathrm{B}_{2} \mathrm{O}_{3}{ }^{20}$.

From Table 1, it can be seen that increasing the content of $\mathrm{Tb}^{3+}$ led to densification of the matrix, as shown by the higher density values. It should be noted that higher density values are reflected in a higher refractive index, resulting in higher Verdet constants, as will be discussed below.

Figure 3 shows the XRD patterns for the BGB- $x$ Tb samples. The diffractograms showed the presence of an amorphous halo and the absence of crystallization peaks, even for the highest $\mathrm{Tb}_{4} \mathrm{O}_{7}$ content. The halo maximum shifted from $27.5^{\circ}$ to $30.5^{\circ}$, while the second halo shifted from $45^{\circ}$ to around $50^{\circ}$, corroborating the structural changes induced by the addition of $\mathrm{Tb}_{4} \mathrm{O}_{7}$, as discussed above.

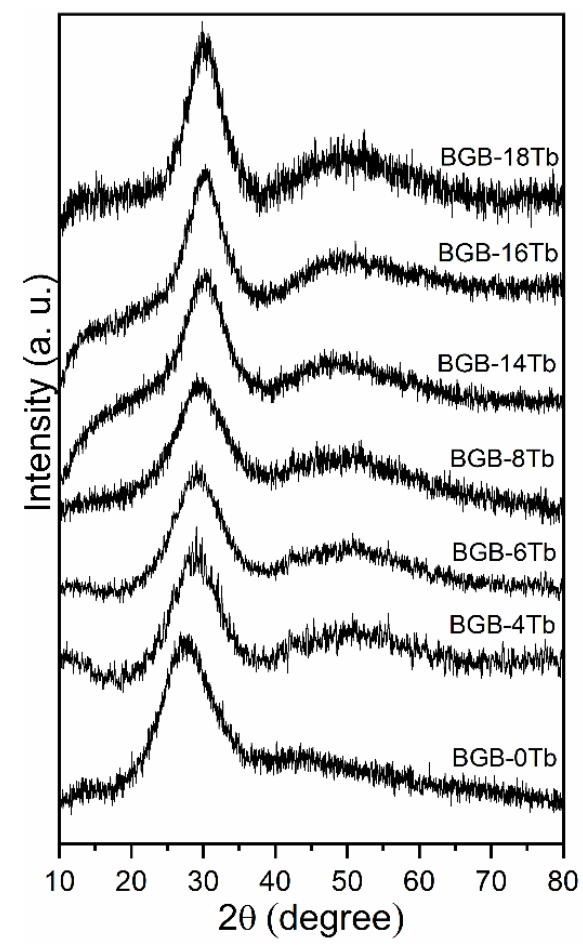

Figure 3. XRD patterns for the BGB- $x$ Tb glasses.

Figure 4(A) shows an HRTEM image of the BGB-18Tb glass, revealing a homogeneous distribution of atoms, with no evidence of clustering at the atomic scale. Fast Fourier transform (FFT) (inset of Figure 4A) confirmed the absence of crystalline spots and the existence of long-range structural order, corroborating the XRD measurements. Figure 4(B) shows a high-angle annular dark-field (HAADF) image of the homogeneous structure of the BGB-18Tb glass (analyzed area) and the corresponding elemental EDS mapping (Ba-K, Tb-L, and $\mathrm{O}-\mathrm{K})$. Figure $\mathrm{S} 1$ shows the EDS spectrum of the BGB-18Tb glass. 

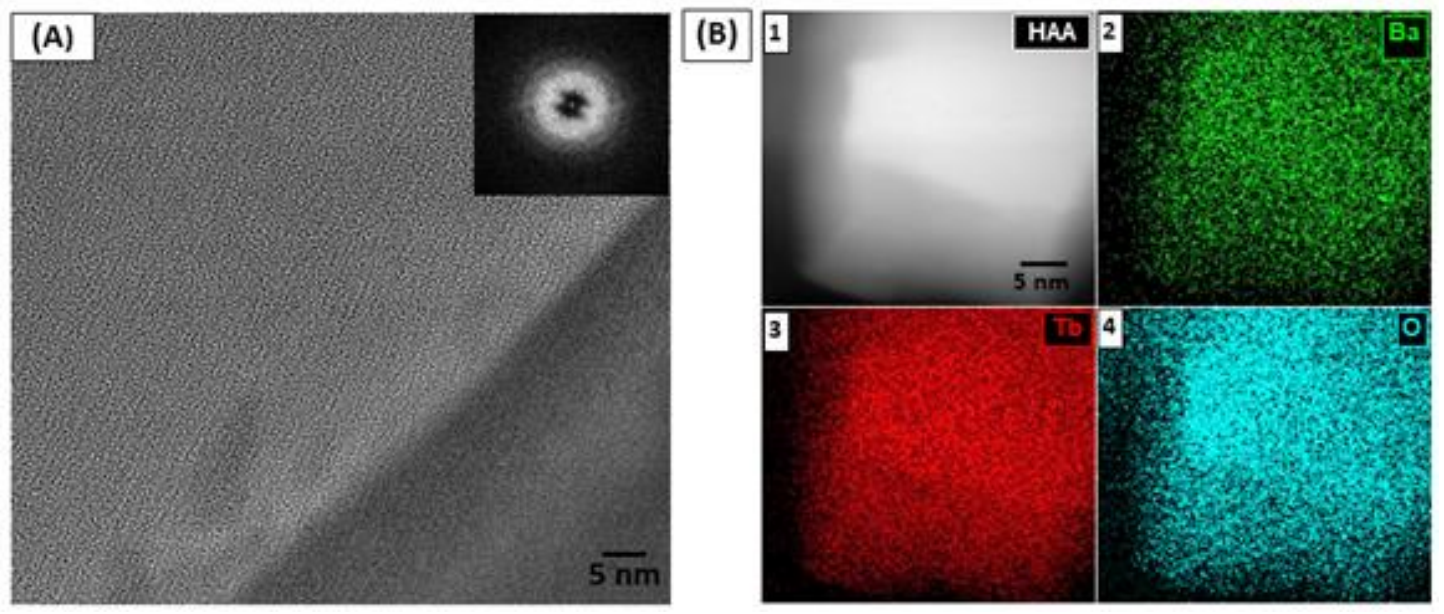

Figure 4. (A) HRTEM micrograph of BGB-18Tb (the inset shows the fast Fourier transform (FFT)). (B) HAADF mode (Z-contrast) image of the analyzed area (1) and elemental EDS mapping for Ba-K (2), Tb-L (3), and O-K (4).

Raman spectroscopy. Raman spectra of all the BGB- $x \mathrm{~Tb}$ glasses are shown in Figure S2(a). The Raman spectrum of the undoped glass (BGB-0Tb) is also plotted to facilitate discussion of the role of $\mathrm{Tb}^{3+}$ ions in the glassy network. Raman spectra of the glass formers $\mathrm{GeO}_{2}$ ( $\alpha$-quartz-like) and $\mathrm{B}_{2} \mathrm{O}_{3}$ (vitreous) are shown in Figure $\mathrm{S} 2(\mathrm{~b})$.

The Raman spectra showed broad bands typical of glassy structures, assigned to a large distribution of bonds and angles, as well as several overlapping vibrational modes of the glass components. For these reasons, it was necessary to identify the contributions of the individual vibrational modes by deconvolution, involving the fitting of Gaussian peaks in different frequency regions of the spectra. Such Gaussian deconvolution has been described in previous spectroscopic studies of germanate, borate, and borogermanate glasses ${ }^{8,20,25,30-36}$.

Raman spectra of the BGB- $x$ Tb glasses at low $\left(\sim 130-700 \mathrm{~cm}^{-1}\right)$, medium $(\sim 650-1050$ $\mathrm{cm}^{-1}$ ), and high (1050-1800 $\left.\mathrm{cm}^{-1}\right)$ frequencies are shown in Figure 5(a-c). Figure 5(d-o) shows the deconvolution at low, medium, and high frequencies for the BGB- $x$ Tb glasses $(x=0,4,8$, and $18 \mathrm{~mol} \%$ of $\mathrm{Tb}_{4} \mathrm{O}_{7}$ ). It can be seen that the addition of $\mathrm{Tb}_{4} \mathrm{O}_{7}$ caused structural changes in the BGB glass network. The main vibrational modes assigned from the Raman spectra for the BGB- $x$ Tb glasses are summarized in Table 2. 

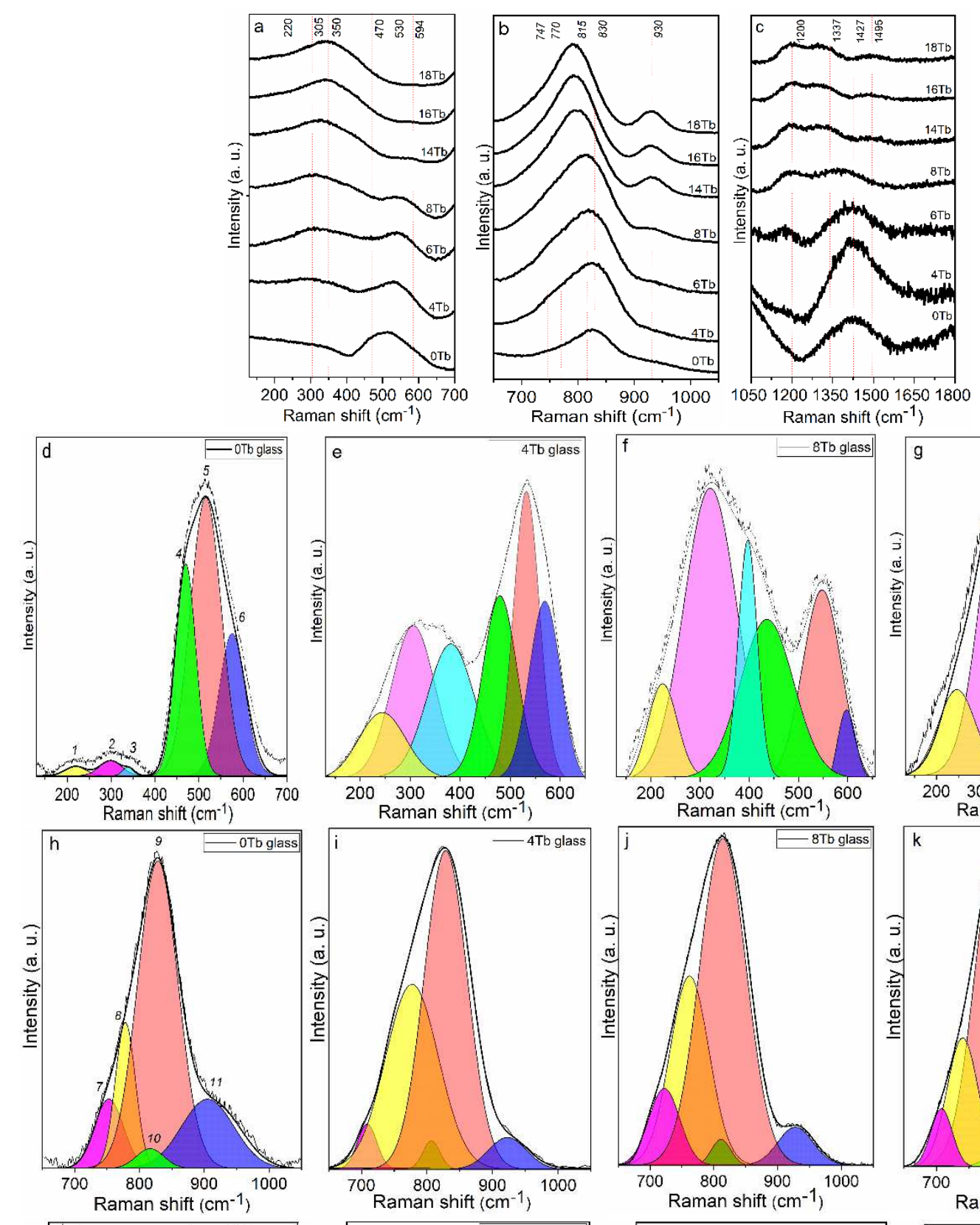
Raman shift $\left(\mathrm{cm}^{-1}\right)$
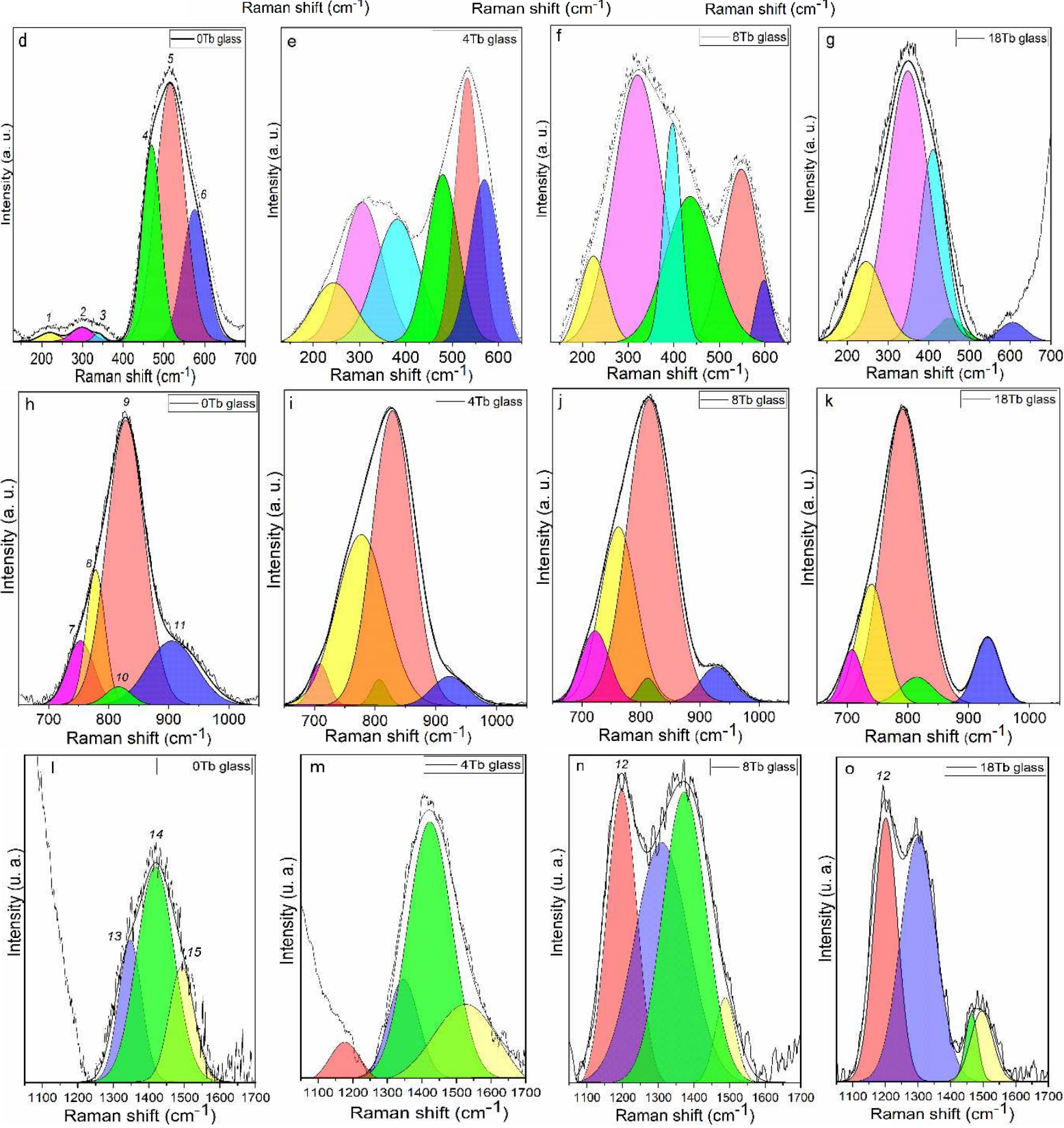

Figure 5. Normalized Raman spectra for the BGB- $x$ Tb glasses in (a) low $\left(\sim 130-700 \mathrm{~cm}^{-1}\right)$, (b) medium ( 650-1050 $\left.\mathrm{cm}^{-1}\right)$, and (c) high $\left(1050-1700 \mathrm{~cm}^{-1}\right)$ frequency regions. Deconvolution of the Raman spectra for the $0,4,8$, and $18 \mathrm{~Tb}$ glasses in the low (d-g), medium (h-k), and high (l-o) frequency regions. 


\begin{tabular}{|c|c|c|c|}
\hline Peaks & Frequencies $\left(\mathrm{cm}^{-1}\right)$ & Vibrational modes & References \\
\hline 1 and 2 & 220 and 305 & $\begin{array}{l}\text { Bending modes of } \mathrm{Ge}-\mathrm{O} \text { in the glassy } \\
\text { network }\end{array}$ & $31-33$ \\
\hline 3 & $340-410$ & $\begin{array}{c}\text { Vibration of } \mathrm{Ge}^{-} \mathrm{O}^{-}(\mathrm{NBO}) \text { corresponding to } \\
\text { the } \mathrm{Q}^{1} \text { species }\end{array}$ & $\begin{array}{c}31,33,34, \\
37\end{array}$ \\
\hline 4 & 470 & $\begin{array}{l}\text { Symmetrical stretching vibrations of Ge-O- } \\
\text { Ge bonds in } 3 \text {-membered } \mathrm{GeO}_{4} \text { rings }\end{array}$ & 35,37 \\
\hline 5 & 520 & $\begin{array}{l}\text { Vibrations of Ge-O-Ge bonds in three- } \\
\text { membered } \mathrm{GeO}_{4}\end{array}$ & $35-37$ \\
\hline 6 & $574-598$ & Symmetrical vibrations of $\mathrm{Ge}-\mathrm{O}-\mathrm{Ge}$ & $35-37$ \\
\hline 7 & 747 & $\begin{array}{l}\text { Symmetrical stretching vibrations of } \\
\text { metaborate chains }\end{array}$ & $32,34,37$ \\
\hline 8 & $740-777$ & $\begin{array}{l}\text { Vibrations of borate rings (di-triborate } \\
\text { rings) }\end{array}$ & $32,34,37$ \\
\hline 9 & $810-820$ & $\begin{array}{l}\text { Symmetrical stretching vibrations of } \mathrm{Ge}^{-} \mathrm{O}^{-} \\
(\mathrm{NBO}) \text { in } \mathrm{Q}^{2} \text { species }\end{array}$ & 36,38 \\
\hline 10 & $790-830$ & $\begin{array}{l}\text { Symmetrical stretching vibrations of } \mathrm{Ge}-\mathrm{O}^{-} \\
(\mathrm{NBO}) \text { in } \mathrm{Q}^{3} \text { species }\end{array}$ & 36,38 \\
\hline 11 & $907-930$ & Vibrational mode of diborate groups & 36 \\
\hline 12 & 1200 & Diborates & 36 \\
\hline 13 & 1337 & $\mathrm{BO}_{3 / 2}$ & 36 \\
\hline 14 & 1427 & $\mathrm{BO}_{3 / 2 \text { ring }}$ & 36 \\
\hline 15 & 1495 & ${\mathrm{~B}-\mathrm{O}^{-}}^{-}$ & 36 \\
\hline
\end{tabular}

Table 2. Assignments of the main vibrational modes for the BGB- $x$ Tb glasses.

Figure 5(d) shows the peak fitting for the undoped BGB glass. In this case, six Gaussian peaks were fitted at low frequencies: 220 (peak 1), 305 (peak 2), 350 (peak 3), 470 (peak 4), 518 (peak 5), and $561 \mathrm{~cm}^{-1}$ (peak 6). In the region below $400 \mathrm{~cm}^{-1}$, peaks 1 and 2 could be attributed to bending modes of Ge-O-Ge in the glassy network ${ }^{32,33}$. Peak 3 could be assigned to the vibration of $\mathrm{Ge}^{-} \mathrm{O}^{-}\left(\mathrm{Q}^{1} \text { species }\right)^{31,33,34,37}$. Peak 4 was assigned to symmetrical stretching 
vibrations of Ge-O-Ge bonds in 3-membered $\mathrm{GeO}_{4}$ rings $^{35,37}$. Between 500 and $600 \mathrm{~cm}^{-1}$, peaks 5 and 6 could be attributed to vibrations of Ge-O-Ge bonds in three-membered $\mathrm{GeO}_{4}$ and symmetrical vibrations of $\mathrm{Ge}-\mathrm{O}-\mathrm{Ge}^{35-37}$. The presence of only $\mathrm{Ge}^{4+}$ in borogermanate glasses was recently elucidated using Ge K-edge EXAFS and XANES measurements ${ }^{8,20}$.

Two main features could be observed after addition of terbium oxide: (I) the intensity of the broad band between 130 and $400 \mathrm{~cm}^{-1}$ increased, and (II) the intensity of the broad band between 500 and $650 \mathrm{~cm}^{-1}$ was strongly attenuated. These behaviors could be explained by the gradual increase of $\mathrm{Ge}^{-} \mathrm{O}^{-}$non-bridge bonds (NBO), due to depolymerization of the BGB glass network after addition of $\mathrm{Tb}^{3+}$ ions. In region $\mathrm{I}$, according to Kamitsos et $\mathrm{al}^{33}$ and Nakamoto ${ }^{37}$, the appearance of vibrational modes at low frequencies $\left(200-400 \mathrm{~cm}^{-1}\right)$ could be assigned to the bending modes of $\mathrm{Q}^{2}$ and $\mathrm{Q}^{1}$ species derived from $\mathrm{GeO}_{4}$ units, as detailed in Figure 5(d-g). In region II, depolymerization increased the NBO number, consequently decreasing the average distribution of $\mathrm{Ge}-\mathrm{O}-\mathrm{Ge}$ bridges.

The deconvolution of the middle region is shown in Figure 5(h-k). Deconvolution of the broad band centered at around $828 \mathrm{~cm}^{-1}$ resulted in the fitting of five peaks centered at around $753,778,815,828$, and $908 \mathrm{~cm}^{-1}$. The first two (peaks 7 and 8 ) were assigned to the symmetrical stretching vibrations of metaborate chains and borate rings (di-triborate rings), respectively ${ }^{32,34,37}$. Previous investigations of germanate and borogermanate glasses using Raman spectroscopy found that the region between 800 and $900 \mathrm{~cm}^{-1}$ was dominated by vibrational modes of $\mathrm{Q}^{2}$ and $\mathrm{Q}^{3}$ units derived from the breakdown of tetrahedral $\left[\mathrm{GeO}_{4}\right]$ units $^{31,32,35-37}$. Peaks $9\left(815 \mathrm{~cm}^{-1}\right)$ and $10\left(828 \mathrm{~cm}^{-1}\right)$ could be attributed to symmetrical stretching vibrations of $\mathrm{Ge}-\mathrm{O}^{-}$in $\mathrm{Q}^{2}$ and $\mathrm{Q}^{3}$ species, respectively ${ }^{36,38}$. In addition, peak 11 ( 908 $\mathrm{cm}^{-1}$ ) was assigned to diborate groups ${ }^{36}$.

As shown in Figure 5(b), the addition of $\mathrm{Tb}_{4} \mathrm{O}_{7}$ shifted the broad band centered at 828 $\mathrm{cm}^{-1}$ (BGB-0Tb glass) to $792 \mathrm{~cm}^{-1}$ (BGB-18Tb glass), while the shoulder at $909 \mathrm{~cm}^{-1}$ in the BGB-0Tb spectrum was shifted to $931 \mathrm{~cm}^{-1}$. Koroleva et al. ${ }^{36}$ used Raman spectroscopy to evaluate the individual contributions of the vibrational modes of $\mathrm{B}_{2} \mathrm{O}_{3}$ and $\mathrm{GeO}_{2}$ in borogermanate glasses. Based on the work of Koroleva et al. ${ }^{36}$ and Kamitsos et al. ${ }^{33}$, the band observed between 900 and $940 \mathrm{~cm}^{-1}$ (peak 11) in the Raman spectra of the borogermanate glasses could be assigned to the vibration of diborate groups.

At higher frequencies (above $1050 \mathrm{~cm}^{-1}$ ), there was a predominance of vibrations of borate groups (Figure 5(c)). The Raman spectrum for the BGB-0Tb glass presented a band at $1200 \mathrm{~cm}^{-1}$ (peak 12), assigned to diborate groups, and a broad band at around $1427 \mathrm{~cm}^{-1}$ with overlapping peaks assigned to asymmetric stretching of $\mathrm{B}-\mathrm{O}$ bonds of $\mathrm{BO}_{3 / 2}$ units (peak 13, at 
$1337 \mathrm{~cm}^{-1}$ ), stretching vibration of $\mathrm{BO}_{3 / 2 \text { ring }}$ (peak 14, at $1427 \mathrm{~cm}^{-1}$ ), and vibrations related to non-bridging oxygen atoms of B-O- bonds (peak 15, at $\left.1495 \mathrm{~cm}^{-1}\right)^{36}$.

The Raman analysis revealed an interesting feature of borogermanate glasses that should be considered in the search for glasses presenting extremely high Verdet constants. $V_{B}$ was shown to be dependent on the $\mathrm{Tb}^{3+}$ ions and increased as a function of the rare earth content. In order to introduce high contents of rare earths into glasses, it is necessary to provide a favorable chemical environment, since rare earths need high coordination number of oxygen atoms to be stabilized and to avoid further precipitation. From comparison of the structures of the glasses studied in this work with other compositions presented in the literature, it could be inferred that increase in the number of NBO can assist in the stabilization of rare earths ${ }^{39}$. For compositions containing lower quantities of NBO, the amounts of rare earths were lower than for those with higher NBO, which was mainly characterized by the intense bands at $\sim 300$ and $820 \mathrm{~cm}^{-1}\left(\mathrm{Ge}-\mathrm{O}^{-}\right)$and above $1050 \mathrm{~cm}^{-1}\left({\mathrm{~B}-\mathrm{O}^{-}}^{-}\right.$. Hence, the use of adequate contents of modifiers such as $\mathrm{BaO}$ is essential for obtaining higher $\mathrm{V}_{\mathrm{B}}$ in borogermanate glasses.

Optical analysis. Figure 6(a) shows the absorption spectra of the BGB- $x$ Tb glasses in the region from 250 to $800 \mathrm{~nm}$. The absorption bands at 318, 340, 350, 358, 370, 378, and 485 $\mathrm{nm}$ were assigned to the $\mathrm{Tb}^{3+} 4 \mathrm{f}-4 \mathrm{f}$ transitions from the ${ }^{7} \mathrm{~F}_{6}$ ground state to the excited states $\left({ }^{5} \mathrm{D}_{0,1},{ }^{5} \mathrm{H}_{7}\right),\left({ }^{5} \mathrm{G}_{2},{ }^{5} \mathrm{~L}_{6}\right),{ }^{5} \mathrm{~L}_{9},{ }^{5} \mathrm{G}_{5},{ }^{5} \mathrm{~L}_{10},\left({ }^{5} \mathrm{D}_{3},{ }^{5} \mathrm{G}_{6}\right)$, and ${ }^{5} \mathrm{D}_{4}$, respectively ${ }^{40}$. 

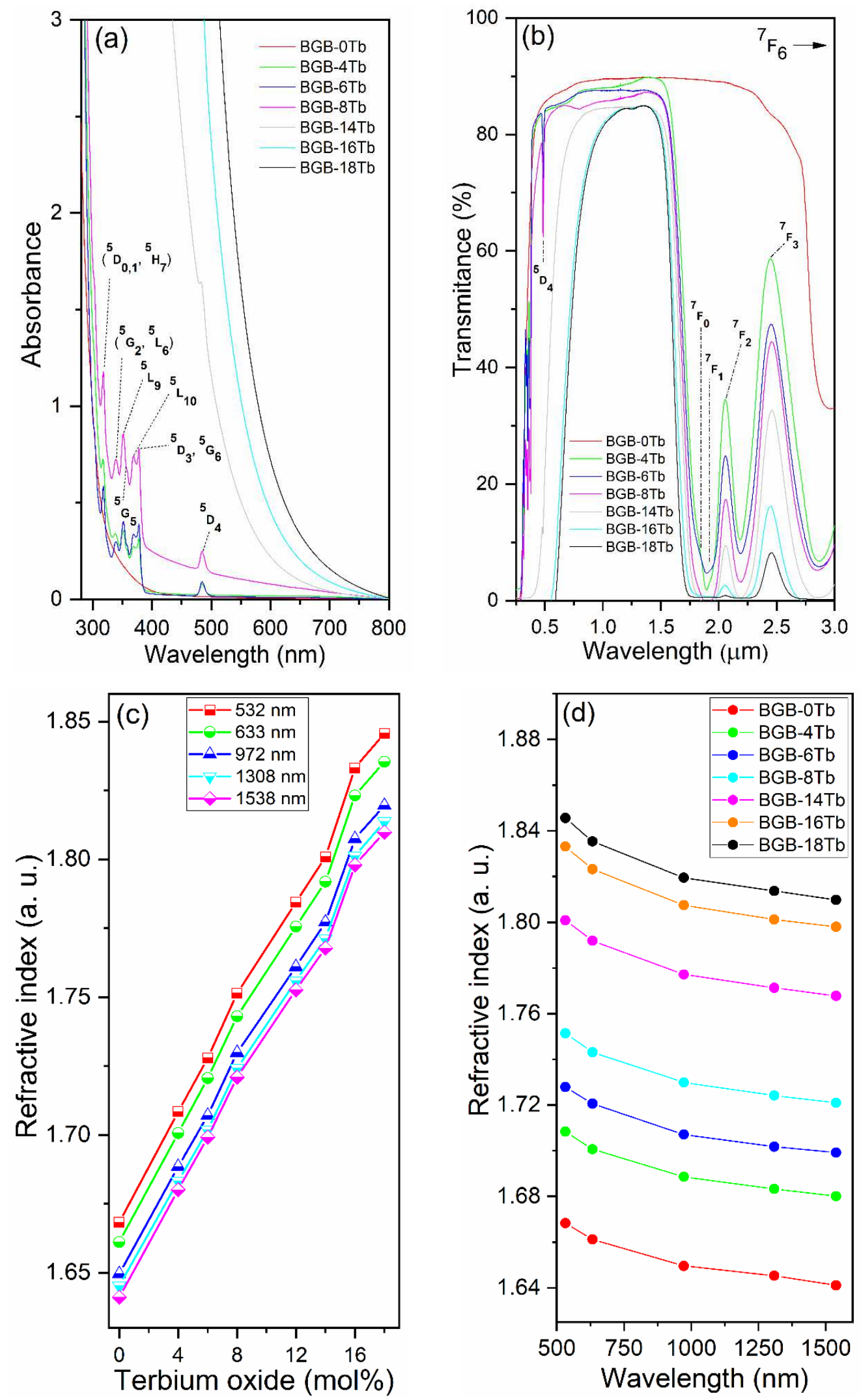

Figure 6. (a) UV-Vis-NIR optical absorption, (b) transmission spectra, (c) refractive indices as a function of $\mathrm{Tb}_{4} \mathrm{O}_{7}$ content, at different wavelengths, and (d) refractive indices for BGB$x \mathrm{~Tb}$ glasses $(0 \leq x \leq 18)$, as a function of wavelength. 
As shown in Figure 6(a), the UV cutoff for the undoped glass was at around $300 \mathrm{~nm}$. The red shift to around $600 \mathrm{~nm}$ (BGB-18Tb), observed after addition of $\mathrm{Tb}_{4} \mathrm{O}_{7}$, was the result of the intense absorption of the $\mathrm{Tb}^{3+}$ transitions. However, the main origin of the red shift could be ascribed to the oxidation of $\mathrm{Tb}^{3+}$ to $\mathrm{Tb}^{4+}$, characterized by the change of color from colorless, passing through pale yellow, and finally to dark brown, as the $\mathrm{Tb}^{3+}$ content increased (see Figure 1$)^{41}$.

Figure 6(b) shows the transmission window for the BGB- $x$ Tb glasses, recorded from UV to NIR. In the visible region, there were the absorption bands assigned to the $4 \mathrm{f}$ electronic transitions of $\mathrm{Tb}^{3+}$ ions. In the NIR region, at 1.84, 1.93, 2.06, and $2.46 \mu \mathrm{m}$, there were the $4 \mathrm{f}$ 4f transitions of $\mathrm{Tb}^{3+}$ ions from the ${ }^{7} \mathrm{~F}_{6}$ ground state to the ${ }^{7} \mathrm{~F}_{0},{ }^{7} \mathrm{~F}_{1},{ }^{7} \mathrm{~F}_{2}$, and ${ }^{7} \mathrm{~F}_{3}$ excited states, respectively ${ }^{20,41}$. It should be highlighted that the BGB- $x$ Tb glasses containing up to $8 \mathrm{~mol} \%$ $\mathrm{Tb}_{4} \mathrm{O}_{7}$ presented optical windows from $0.5 \mu \mathrm{m}$ up to $1.60 \mu \mathrm{m}$.

Figure 6(c) shows the refractive indices $(n)$ for the BGB- $x$ Tb samples, in the visible and near-infrared regions, as a function of $\mathrm{Tb}_{4} \mathrm{O}_{7}$ content. It can be seen that increase of the $\mathrm{Tb}_{4} \mathrm{O}_{7}$ concentration resulted in a higher value of $n$, mainly due to the high polarizability of the $\mathrm{Tb}^{3+}$ ions. The maximum $n$ obtained was 1.8457 at $532 \mathrm{~nm}$, for the BGB-18Tb glass. Figure 6(d) shows the refractive indices as a function of wavelength. The curve profiles showed that decrease of $n$ was associated with increase of the wavelength, indicative of chromatic dispersion $^{42}$.

Luminescence analysis. Figure 7(a-b) shows the photoexcitation (PLE) and luminescence (PL) spectra of $\mathrm{Tb}^{3+}$ in the BGB- $x \mathrm{~Tb}$ glasses at room temperature. Figure 7(a) shows the PLE spectrum of the BGB-4Tb glass excited at $545 \mathrm{~nm}$. Overlapping was observed of PLE bands in the UV-Vis region at 483, 375, 370, 357, 350, 339, 325, 316, 301, and $284 \mathrm{~nm}$, corresponding to $4 \mathrm{f}^{8} \rightarrow 4 \mathrm{f}^{8}$ electronic transitions from the ${ }^{7} \mathrm{~F}_{6}$ ground state to the labeled excited states ${ }^{43}$. The most intense band at $375 \mathrm{~nm}$, assigned to the ${ }^{7} \mathrm{~F}_{6} \rightarrow{ }^{5} \mathrm{D}_{3}$ transition, was used as the excitation wavelength for acquisition of the emission spectra shown in Figure 7(b). 

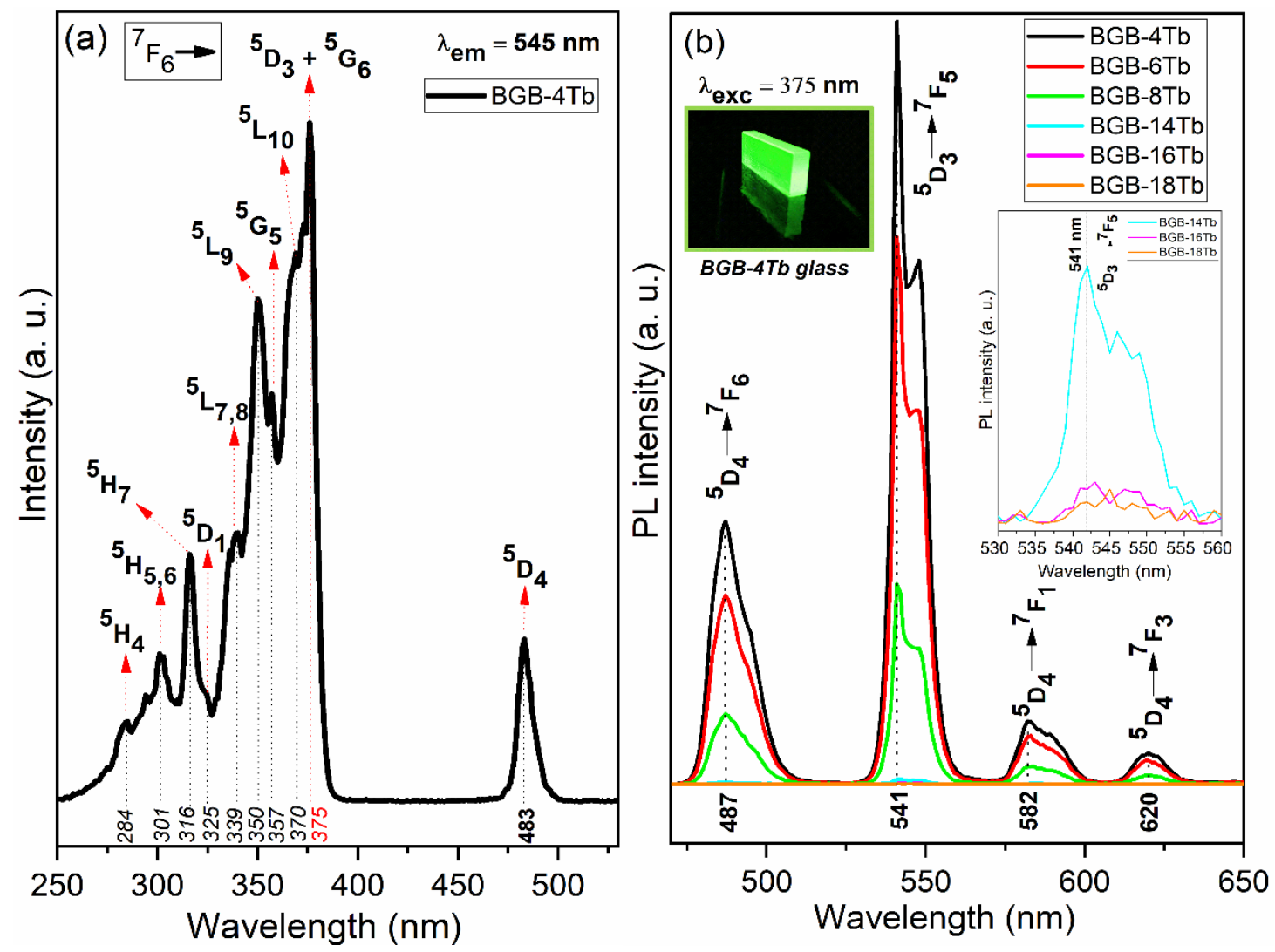

Figure 7. (a) PLE spectrum of the BGB-4Tb glass and (b) PL spectra of the BGB- $x \mathrm{~Tb}$ glasses at room temperature. Inset photograph: BGB-4Tb sample under excitation at 375 nm. Inset: PL spectra of the BGB-xTb glasses $\left(x=14,16\right.$, and $\left.18 \mathrm{~mol}^{2} \mathrm{~Tb}_{4} \mathrm{O}_{7}\right)$ in the region from 530 to $560 \mathrm{~nm}$.

Four emission bands at 487, 541, 582, and $620 \mathrm{~nm}$ were assigned to the transitions from ${ }^{5} \mathrm{D}_{4}$ to $\left.{ }^{7} \mathrm{~F}_{\mathrm{j}} \mathrm{j}=6,5,4,3\right)$ multiplet ${ }^{44}$. Comparison of all the PL bands of the $\mathrm{Tb}^{3+}$ ions in the BGB glasses showed the same spectral profile for all the samples, although the intensities of the PL bands differed, since strong quenching in BGB glasses is observed with increase of the $\mathrm{Tb}_{4} \mathrm{O}_{7}$ concentration. This fluorescence quenching is due to greater interaction between the RE ions present at higher concentrations, with shorter distances between neighboring ions $\left(\mathrm{Tb}^{3+}-\mathrm{Tb}^{3+}\right)$ in the bulk glass ${ }^{45}$. The inset in Figure 7(b) highlights the low intensity emission assigned to the electronic transition at $541 \mathrm{~nm}$ for the BGB- $x$ Tb glasses $(x=14,16$, and $18 \mathrm{~mol} \%$ $\mathrm{Tb}_{4} \mathrm{O}_{7}$ ) in the range between 530 and $560 \mathrm{~nm}$.

Figure $\mathrm{S} 3$ shows the normalized luminescence decay curves for the ${ }^{5} \mathrm{D}_{4} \rightarrow{ }^{5} \mathrm{~F}_{7}$ emission of $\mathrm{Tb}^{3+}$ ions for the BGB glasses containing $x=4,6,8$, and $14 \mathrm{~mol}_{\%} \mathrm{~Tb}_{4} \mathrm{O}_{7}$, obtained by monitoring of the green emission at $545 \mathrm{~nm}$, with excitation at $375 \mathrm{~nm}$. The decay times for the the BGB- $x \operatorname{Tb}(x=16$ and 18) glasses are not shown, due to the strong quenching. The decay 
curves presented a single exponential profile, described by $I(t)=I_{0} \exp (-t / \tau)$, where $\tau$ (in $\mathrm{ms}$ ) is the lifetime. The graph inserted in Figure S3(c) shows the fluorescence decay time as a function of $\mathrm{Tb}_{4} \mathrm{O}_{7}$ concentration, where $\tau$ decreased with increase of the $\mathrm{Tb}^{3+}$ content from $1.38 \mathrm{~ms}(x=$ $4 \mathrm{~Tb})$ to $0.175 \mathrm{~ms}(x=14 \mathrm{~Tb})$.

Magneto-optical properties and Verdet constant $\left(\mathbf{V}_{\mathbf{B}}\right)$. In this work, BGB glasses containing high concentrations of $\mathrm{Tb}^{3+}$ ions showed accentuated Faraday rotation effects in the visible and NIR regions. The theory underlying the Faraday effect in glasses is based on the Zeeman effect when the material is submitted to a magnetic field ${ }^{9,11}$. The magnitude of the Faraday effect in a magneto-optical material is evaluated by calculation of the Verdet constant $\left(V_{B}\right)^{9}$.

Figure 8(a) shows the set of transparent BGB- $x \mathrm{~Tb}$ bulk glasses and the magnetic attraction of the BGB-18Tb glass using a commercial neodymium-based magnet (N42 grade). This interesting attraction phenomenon is a qualitative way to demonstrate the paramagnetic properties of BGB- $x \mathrm{~Tb}$ bulk glasses. All the glasses studied here could be lifted using the $\mathrm{Nd}$ magnet. A video showing the attraction effect is provided with the online version of the manuscript.

Figure 8(b-c) shows the $\mathrm{V}_{\mathrm{B}}$ values as a function of the concentration of $\mathrm{Tb}_{4} \mathrm{O}_{7}$ (in $\mathrm{mol}_{\%}$ ) and the $\mathrm{Tb}^{3+}$ ion density (in $10^{21}$ ions $\mathrm{cm}^{-3}$ ) for all the glasses, at different wavelengths. The increase of the $\mathrm{V}_{\mathrm{B}}$ values with the $\mathrm{Tb}_{4} \mathrm{O}_{7}$ content is shown in Figure 8(b). The $\mathrm{V}_{\mathrm{B}}$ values obtained were negative, indicating right-handed rotation of the polarized light, characteristic of paramagnetic materials. 


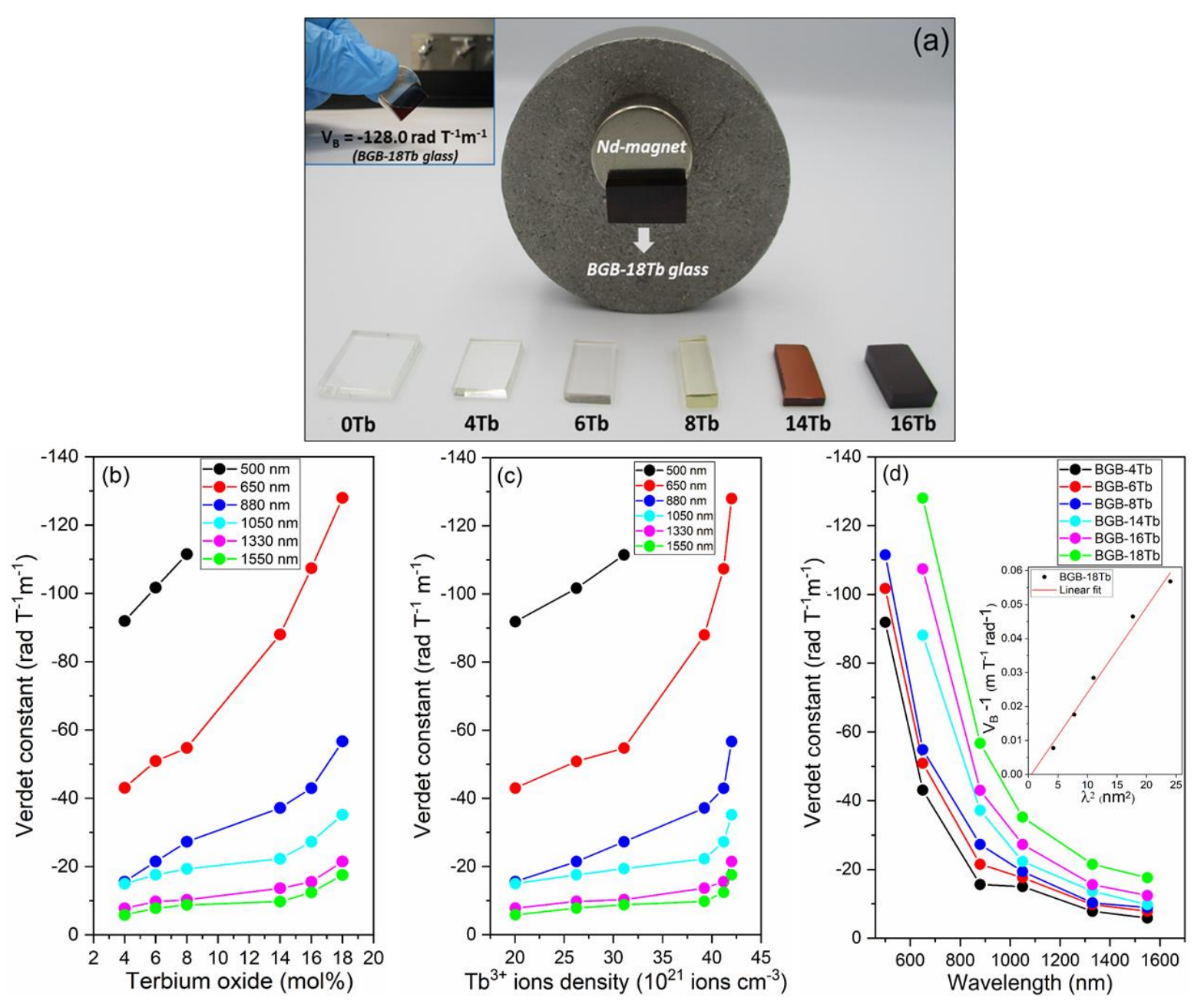

Figure 8. (a) Photographs of the BGB- $x$ Tb glasses and the magnetic attraction of the BGB$18 \mathrm{~Tb}$ glass using a commercial neodymium magnet. Plots of $\mathrm{V}_{\mathrm{B}}$ as a function of (b) $\mathrm{Tb}_{4} \mathrm{O}_{7}$ content (mol\%), (c) $\mathrm{Tb}^{3+}$ ions density $\left(\mathrm{g} \mathrm{cm}^{-3}\right)$, and (d) wavelength.

In studies of the MO properties of RE-doped glasses, the $V_{B}$ values are generally expressed as a function of the RE ion density $\left(N_{R E \text { ion }}\right)$. In this work, the $\mathrm{Tb}^{3+}$ ion densities $\left(N_{T b^{3+}}\right)$ for all glasses were calculated using Equation (1) and are shown in Table 1.

Progressive increase of the $\mathrm{Tb}^{3+}$ content led to improvement of the magneto-optical properties of the glasses (Figure 8(c)), as confirmed by increase of the $\mathrm{V}_{\mathrm{B}}$ values. At $500 \mathrm{~nm}$, $\mathrm{V}_{\mathrm{B}}$ for the BGB-8Tb glass was $-111.5 \mathrm{rad} \mathrm{T}^{-1} \mathrm{~m}^{-1}$, while the $\mathrm{V}_{\mathrm{B}}$ values at $650 \mathrm{~nm}$ for the BGB4Tb and BGB-18Tb glasses were -43.0 and $-128.0 \mathrm{rad} \mathrm{T}^{-1} \mathrm{~m}^{-1}$, respectively. At $650 \mathrm{~nm}$, the BGB-18Tb glass had the highest $V_{\text {B }}$ value among all the glasses studied in this work. The observed values were consistent with those reported in the literature for other borogermanate glasses $^{1,22}$. In addition, comparison of the $V_{B}$ values for the BGB-18Tb glass and the TGG 
reference, at $650 \mathrm{~nm}$, showed that the $\mathrm{V}_{\mathrm{B}}$ of the glass was only $2.3 \%$ higher than the value for TGG $\left(\mathrm{V}_{\mathrm{B}}=-125 \mathrm{rad} \mathrm{T}^{-1} \mathrm{~m}^{-1}\right)^{19}$.

The MO effect of glasses containing high $\mathrm{Tb}^{3+}$ contents is due to the unfilled $4 \mathrm{f}$ electron layer of $\mathrm{Tb}$ atoms, since the unpaired $4 \mathrm{f}$ electrons generate random magnetic moments, consequently inducing a strong paramagnetic effect. In other words, for $\mathrm{Tb}^{3+}$, the high magnetic moment and the paramagnetic effect are produced from $4 \mathrm{f} \rightarrow 4 \mathrm{f}^{\mathrm{n}-1} 5 \mathrm{~d}$ energy level transitions ${ }^{11,46}$. In general terms, the Verdet constant for MO glass can be described by the sum of the contributions of paramagnetic and diamagnetic components, according to Equation (3) ${ }^{13}$ :

$$
V_{B}=V_{\text {paramag }}+V_{\text {diamag }}
$$

where, $V_{\text {paramag }}$ and $V_{\text {diamag }}$ are the Verdet constants for the paramagnetic and diamagnetic contributions. Therefore, when $V_{\text {paramag }}$ is higher than $V_{\text {diamag }}$, the MO glass is predominantly paramagnetic. As discussed before, a useful way to increase the $V_{\text {paramag }}$ component in a MO glass is by adding paramagnetic species such as $\mathrm{Tb}^{3+}, \mathrm{Dy}^{3+}$, or $\mathrm{Mn}^{2+}$ ions ${ }^{1,7,47}$. The proportional inverse relationship between $V_{\text {paramag }}$ and wavelength can be expressed as shown in Equation $(4)^{13}$ :

$$
V_{\text {paramag }}(\lambda)=\frac{A}{\lambda_{t}^{2}-\lambda^{2}}
$$

where, $A, \lambda$, and $\lambda_{t}$ are approximation parameters and are given as the incident light and the effective transition wavelengths, respectively ${ }^{13}$. Figure $8(d)$ shows the inverse relation between $\mathrm{V}_{\text {в }}$ and wavelength for all the BGB- $x$ Tb samples, as described by Equation 4 .

The Figure $8(\mathrm{~d})$ inset shows the relationship between $1 / V_{B}$ and $\lambda^{2}$ for the BGB-18Tb glass data. The value of $\lambda_{t}$ was obtained as the intersection of the straight line on the $\mathrm{x}$-axis $\left(\lambda^{2}\right)$, obtained from linear fitting of $1 / N_{B} v s . \lambda^{2}$. In this case, the value of the effective transition wavelength $\left(\lambda_{t}\right)$ for the BGB-18Tb glass was $228 \mathrm{~nm}$, which was close to the $4 \mathrm{f}^{8} \leftrightarrow 4 \mathrm{f}^{7} 5 \mathrm{~d}$ electron energy level transition of $\mathrm{Tb}^{3+}$, specifically the ${ }^{7} \mathrm{~F}_{6}-{ }^{7} \mathrm{D}_{5}$ level transition between 220 and $250 \mathrm{~nm}^{48}$. The $\lambda_{t}$ value of $228 \mathrm{~nm}$ for the BGB-18Tb glass was similar to values reported for other glass systems such as fluorophosphate $(\sim 217 \mathrm{~nm})^{49}$, borogermanate $(225-300 \mathrm{~nm})^{1}$, sodium borate $(\sim 220 \mathrm{~nm})^{50}, \mathrm{~Tb}^{3+}$-doped phosphate $(\sim 250 \mathrm{~nm})^{51}$, aluminoborate $(\sim 250 \mathrm{~nm})^{52}$, and borosilicate $(\sim 259-280 \mathrm{~nm})^{53}$. 
The main wavelengths for applications of MO glasses are in the infrared range, between 1.05 and $1.33 \mu^{54}$. Figure $8(d)$ shows the $V_{B}$ values obtained for all the glasses at 1.03, 1.33, and $1.55 \mu \mathrm{m}$. It should be highlighted that the maximum $V_{B}$ value at $1550 \mathrm{~nm}$ (in the telecommunications range) was $-17.6 \mathrm{rad} \mathrm{T}^{-1} \mathrm{~m}^{-1}$, which was 37 -fold higher than the $\mathrm{V}_{\mathrm{B}}$ of silica glass $\left(\sim 0.471 \mathrm{rad} \mathrm{T}^{-1} \mathrm{~m}^{-1}\right)^{55}$.

For practical purposes, the absorption of the glass in the spectral region employed should be minimized. As observed in this work, the optical window diminishes as a function of the terbium content, mainly due to the oxidation of $\mathrm{Tb}^{3+}$ to $\mathrm{Tb}^{4+}$, which occurs at high temperature. However, this problem can be mitigated by the addition of reducing agents such as $\mathrm{Ce}_{2} \mathrm{O}_{3}$, as shown in Figure $\mathrm{S} 4$, which allow broadening of the optical window in the visible range. As can be seen, the addition of $0.5 \mathrm{~mol} \% \mathrm{Ce}_{2} \mathrm{O}_{3}$ was sufficient to maintain the reduced conditions necessary to avoid oxidation of $\mathrm{Tb}^{3+}$ to $\mathrm{Tb}^{4+}$, without significantly affecting other thermal and structural properties. With this approach, it was possible to shift the absorption band from 0.75 to $0.55 \mu \mathrm{m}$ and obtain a glass that was light yellow in color, rather than dark brown, as shown in the inset in Figure S4.

Fabrication of magneto-optical glass fiber. Figure 9(a-b) shows photographs of the polished glass preform and the optical fiber obtained by applying the drawing process to the BGB-8Tb glass. Among all the BGB glasses analyzed, the BGB-8Tb glass presented the highest $\Delta \mathrm{T}$, so for this reason it was selected for production of the magneto-optical fiber. The BGB-8Tb fiber was coated with poly(methyl methacrylate) (PMMA) and the length of the fiber obtained was around $50 \mathrm{~m}$ (Figure 9(b)). 


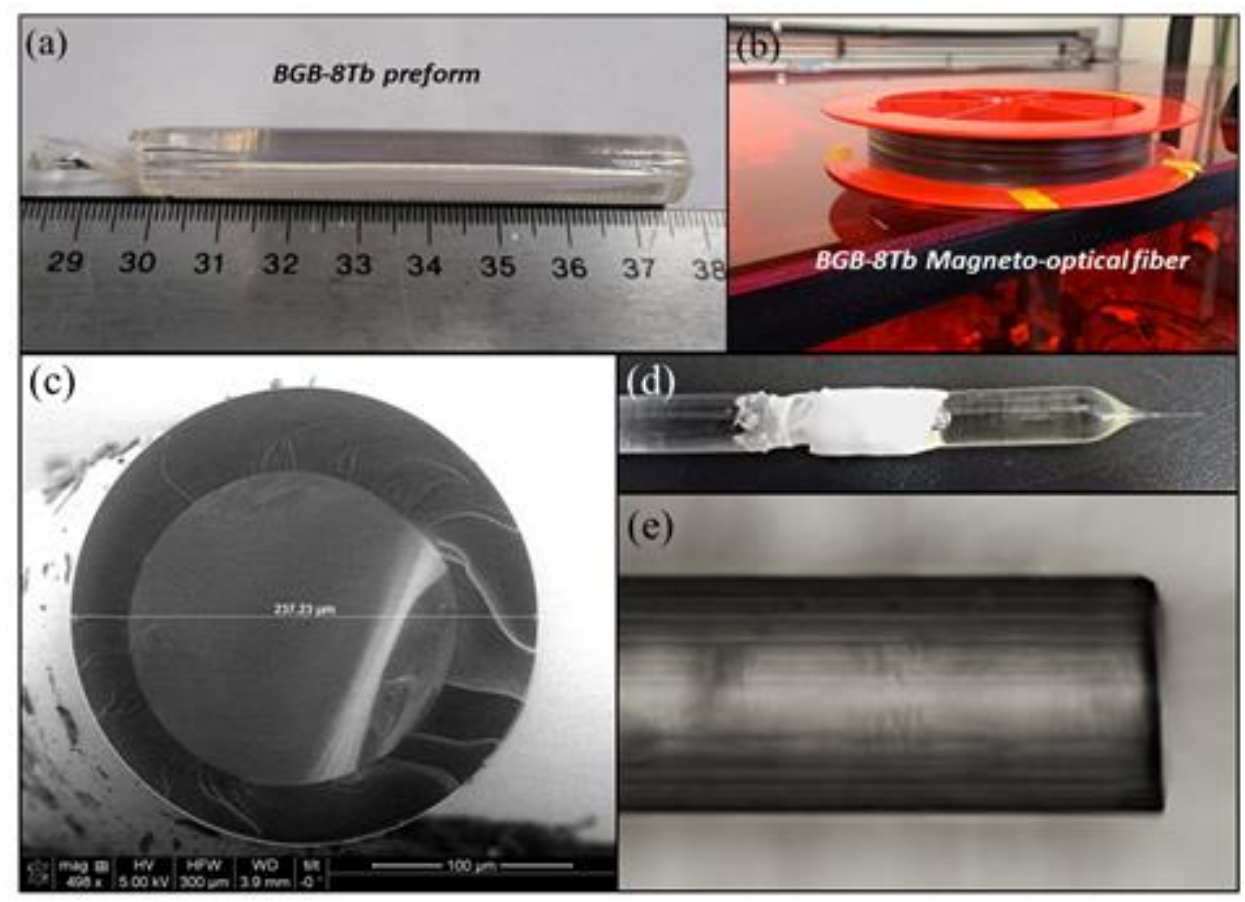

Figure 9. (a) Glass preform, (b) MO fiber based on the BGB-8Tb composition, (c) SEM crosssection image of the BGB-8Tb fiber, (d) glass preform after the drawing process, and (e) optical microscopy image of the surface of the fiber.

Figure 9(c) shows an SEM cross-section image of the optical fiber with diameter of around $237 \mu \mathrm{m}$. The refractive index of the BGB-8Tb fiber was 1.7514 , measured at $532 \mathrm{~nm}$. This value was the same as obtained for the corresponding bulk sample.

Figure 9(d-e) shows photographs of the preform after the drawing process and the surface of the optical fiber, respectively. In neither case was there any evidence of crystallization on the surface after the drawing process.

Magneto-optical and optical fiber characterizations. Figure 10 (a) shows the $V_{B}$ values for the BGB-8Tb fiber according to wavelength. The $\mathrm{V}_{\mathrm{B}}$ values obtained in the visible range at 500 and $650 \mathrm{~nm}$ were -110.2 and $58.8 \mathrm{rad} \mathrm{T}^{-1} \mathrm{~m}^{-1}$, respectively. In the NIR range, the $\mathrm{V}_{\mathrm{B}}$ values were $-32.2,-22.8,-15.2$, and $-9.5 \mathrm{rad} \mathrm{T}^{-1} \mathrm{~m}^{-1}$ at $880,1050,1330$, and $1550 \mathrm{~nm}$, respectively. Comparison with $V_{B}$ values at $650-660 \mathrm{~nm}$ reported in the literature showed that the $V_{B}$ values for the BGB-8Tb fiber were higher than for $\mathrm{Eu}^{3+}$-doped silica ${ }^{11}\left(-4.564 \mathrm{rad} \mathrm{T}^{-1} \mathrm{~m}^{-1}\right), \mathrm{Er}^{3+}$-doped silica $(E D F)^{11}\left(-3.379 \mathrm{rad} \mathrm{T}^{-1} \mathrm{~m}^{-1}\right), \mathrm{Ho}^{3+}$-doped silica ${ }^{23}\left(-23.6 \mathrm{rad} \mathrm{T}^{-1} \mathrm{~m}^{-1}\right)$, and $\mathrm{Tb}^{3+}$-doped borogermanate ${ }^{20}\left(-23.6 \mathrm{rad} \mathrm{T}^{-1} \mathrm{~m}^{-1}\right)$. However, at $1053 \mathrm{~nm}, \mathrm{~V}_{\mathrm{B}}$ obtained here was lower than for silicate fibers containing 56 and $65 \mathrm{wt} \% \mathrm{~Tb}^{3+}$ ions, for which the values were -24 and -32 $\operatorname{rad~T}^{-1} \mathrm{~m}^{-1}$, respectively ${ }^{17,24}$. It should be highlighted that the $\mathrm{V}_{\mathrm{B}}$ values for the BGB-8Tb fiber 
at 1050 and $1550 \mathrm{~nm}\left(-22.8\right.$ and $-9.5 \mathrm{rad} \mathrm{T}^{-1} \mathrm{~m}^{-1}$, respectively) were nineteen and sixteen times higher than for a single-mode optical fiber (SMF) $\left(V_{B} \sim 0.589 \mathrm{rad} \mathrm{T}^{-1} \mathrm{~m}^{-1} \text { at } 1550 \mathrm{~nm}\right)^{17,24}$.
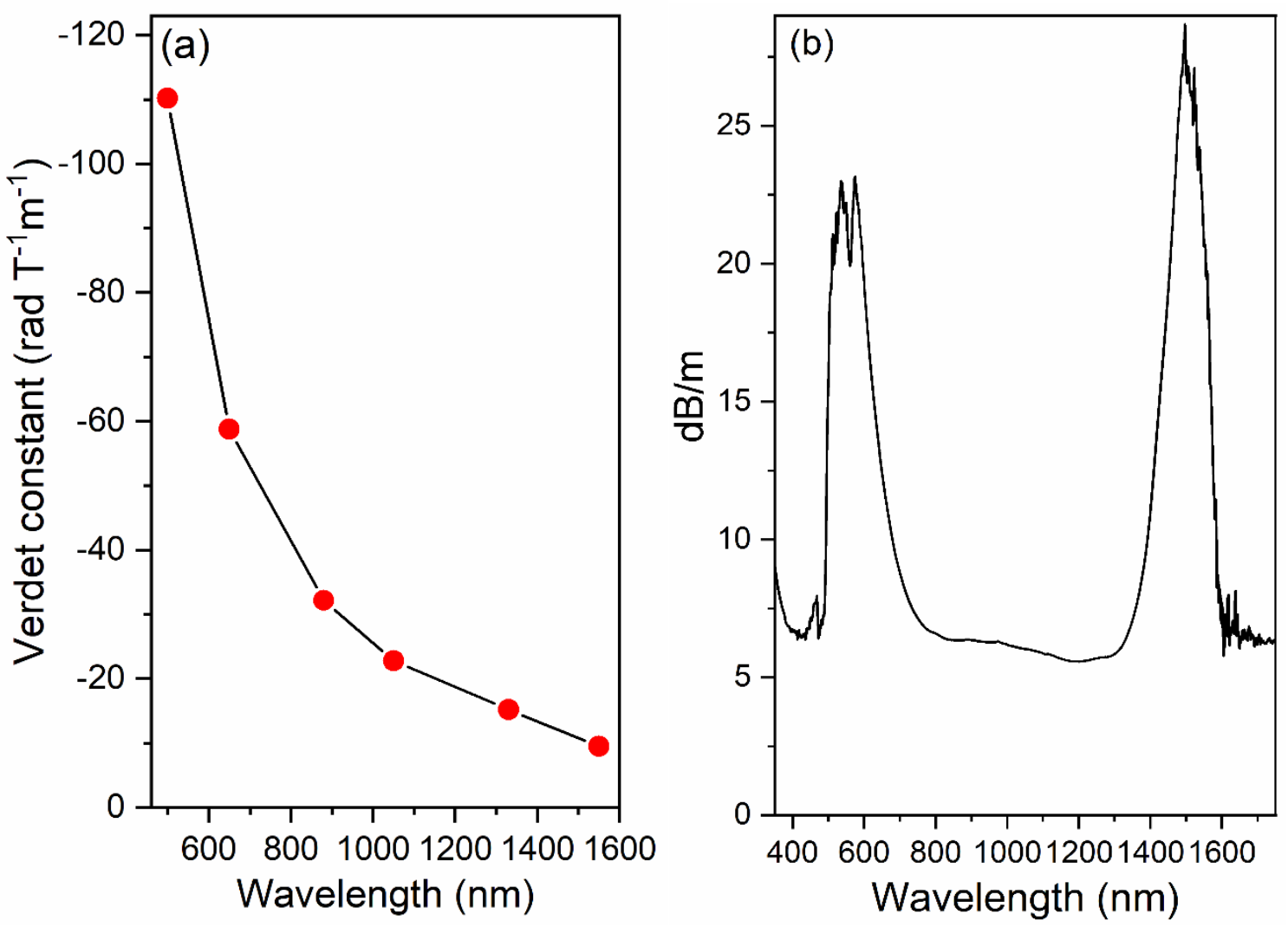

Figure 10. (a) Variation of the Verdet constant as a function of wavelength and (b) attenuation spectrum of the BGB-8Tb fiber determined using the cut-back method, with a final length of $0.21 \mathrm{~cm}$.

Figure 10(b) shows the attenuation spectrum of the BGB-8Tb fiber, revealing two main optical losses in the ranges 350-500 $\mathrm{nm}$ and 1400-1750 $\mathrm{nm}$. As observed in the transmission spectra for the BGB- $x$ Tb bulk glasses (Figure $6 \mathrm{~b}$ ), there were intrinsic absorptions in UV-VisNIR regions, attributed to the $\mathrm{Tb}^{3+}$ ions. Using the cut-back method (from $1.92 \mathrm{~m}$ to $0.21 \mathrm{~cm}$ fiber length), the minimum attenuation of $6.4 \mathrm{~dB} \mathrm{~m}^{-1}$ was obtained at around $880 \mathrm{~nm}$ (Figure 10(b)). The main sources of fiber attenuation include the glass preform preparation process, traces of impurities, water absorption, glass striae, and fiber imperfections.

Among the optical fibers reported in the literature, pure silica fibers are known to provide high performance, due to low attenuation in the NIR region ${ }^{56}$. On the other hand, silica fibers have very low $V_{B}$ values in the NIR region ${ }^{11}$. For example, $V_{B}$ of $\sim 2.05 \mathrm{rad} \mathrm{T}^{-1} \mathrm{~m}^{-1}$ was found for an SMF at $830 \mathrm{~nm}^{57}$. In this work, the BGB-8Tb fiber presented $\mathrm{V}_{\mathrm{B}}$ of $-32.2 \mathrm{rad} \mathrm{T}^{-1}$ 
$\mathrm{m}^{-1}$ at $880 \mathrm{~nm}$, which was around 15 -fold higher than obtained for the $\mathrm{SMF}^{57}$. In magnetooptical terms, the BGB-8Tb fiber has good potential for application in the so-called "first optical window" at around $820-900 \mathrm{~nm}$, given its high $\mathrm{V}_{\mathrm{B}}$ value at $880 \mathrm{~nm}^{58}$.

\section{Conclusions}

This work reports the synthesis of transparent $\mathrm{Tb}^{3+}$-borogermanate $\mathrm{MO}$ glasses using the traditional melt-quenching method. The thermal, structural, morphological, spectroscopic, optical, and magnetic-optical properties of the glasses were investigated. Structural changes in the glass network, following the addition of $\mathrm{Tb}_{4} \mathrm{O}_{7}$, were confirmed by Raman spectra of the BGB- $x \mathrm{~Tb}$ glasses, showing the presence of vibrations assigned to nonbridging oxygen bonds, such as $\mathrm{Ge}^{-} \mathrm{O}^{-}$in $\mathrm{Q}^{2}$ and $\mathrm{Q}^{3}$ species, and $\mathrm{B}-\mathrm{O}^{-}$. The morphological analyses showed that at high $\mathrm{Tb}^{3+}$ content, the BGB- $x \mathrm{~Tb}$ system was free of nanocrystals. The absence of crystals and high thermal stability of the glass containing $8 \mathrm{~mol} \%$ of $\mathrm{Tb}_{4} \mathrm{O}_{7}(305$ ${ }^{\circ} \mathrm{C}$ ) allowed the production of an MO fiber. The magnitude of the Faraday effect in the BGB$x \mathrm{~Tb}$ glasses was evaluated from the $\mathrm{V}_{\mathrm{B}}$ values in the visible and NIR regions. Here, it should be emphasized that the $\mathrm{V}_{\mathrm{B}}$ values for the BGB- $x \mathrm{~Tb}$ glasses were investigated in the NIR region, between 880 and $1550 \mathrm{~nm}$. An important finding was that the maximum $\mathrm{V}_{\text {B }}$ value at $1550 \mathrm{~nm}$ was $-17.6 \mathrm{rad} \mathrm{T}^{-1} \mathrm{~m}^{-1}$, which was 37 times higher than for silica glasses. The maximum Verdet constant value for the BGB-18Tb glass at $650 \mathrm{~nm}$ was $-128 \mathrm{rad} \mathrm{T}^{-1} \mathrm{~m}^{-1}$. For the BGB-8Tb optical fiber, $V_{B}$ at $1550 \mathrm{~nm}$ (telecommunications range) was $-9.5 \mathrm{rad} \mathrm{T}^{-1} \mathrm{~m}^{-1}$, which was 16 times higher than $V_{B}$ for silica glass. The lowest optical loss of $10 \mathrm{~dB} \mathrm{~m}^{-1}$ and $V_{B}$ of $-32.2 \mathrm{rad}$ $\mathrm{T}^{-1} \mathrm{~m}^{-1}$ were measured at $880 \mathrm{~nm}$. In summary, the BGB- $x \mathrm{~Tb}$ system provides a set of MO glasses with potential to produce Faraday rotator fibers.

\section{Methods}

Synthesis. $\mathrm{Tb}^{3}$-doped borogermanate glasses were prepared by the conventional meltquenching method, using chemical-grade germanium oxide $\mathrm{GeO}_{2}$ (Sigma-Aldrich), boric acid $\left(\mathrm{H}_{3} \mathrm{BO}_{3}\right.$, Sigma-Aldrich), aluminum oxide $\left(\mathrm{Al}_{2} \mathrm{O}_{3}\right.$, Sigma-Aldrich), sodium carbonate ( $\mathrm{Na}_{2} \mathrm{CO}_{3}$, Sigma-Aldrich), barium carbonate $\left(\mathrm{BaCO}_{3}\right.$, Sigma-Aldrich), and terbium oxide ( $\mathrm{Tb}_{4} \mathrm{O}_{7}$, Sigma-Aldrich).

The chemicals were stoichiometrically weighed to yield $10 \mathrm{~g}$ of a glass with molar composition of $(100-x)\left(41 \mathrm{GeO}_{2}-25 \mathrm{~B}_{2} \mathrm{O}_{3}-4 \mathrm{Al}_{2} \mathrm{O}_{3}-10 \mathrm{Na}_{2} \mathrm{O}-20 \mathrm{BaO}\right)-x \mathrm{~Tb}_{4} \mathrm{O}_{7}$ (BGB- $\left.x \mathrm{~Tb}\right)$, 
where $x=0,4,6,8,14,16$, and 18 mol\%. The samples were labeled as BGB-xTb. All the compositions are summarized in Table 1.

In the first step, vitreous boron oxide was obtained by thermal decomposition of $\mathrm{H}_{3} \mathrm{BO}_{3}$ at $500{ }^{\circ} \mathrm{C}$ for $30 \mathrm{~min}$ in a resistive furnace. The glass components were ground to fine powder and homogenized in an agate mortar. Batches were loaded into a platinum crucible and melted at between 1350 and $1500{ }^{\circ} \mathrm{C}$ (depending on the $\mathrm{Tb}_{4} \mathrm{O}_{7}$ content), for $2 \mathrm{~h}$, under atmospheric conditions. The melt was cooled in a preheated stainless steel mold at $30^{\circ} \mathrm{C}$, below the glass transition temperature $\left(\mathrm{T}_{\mathrm{g}}\right)$, and then annealed at the same temperature for $3 \mathrm{~h}$, to minimize its mechanical stress, followed by slowly cooling to room temperature during $12 \mathrm{~h}$. Pieces with thickness of $3 \mathrm{~mm}$ were obtained. As a final step, the samples were polished using silicon carbide $(\mathrm{SiC})$ polishing papers, prior to the optical characterizations.

The glass preform based on the composition $92\left(41 \mathrm{GeO}_{2}-25 \mathrm{~B}_{2} \mathrm{O}_{3}-4 \mathrm{Al}_{2} \mathrm{O}_{3}-10 \mathrm{Na} 2 \mathrm{O}-\right.$ $20 \mathrm{BaO})-8 \mathrm{~Tb}_{4} \mathrm{O}_{7}(\mathrm{BGB}-8 \mathrm{~Tb}$ ) was selected for use in the fiber drawing process, because it showed the highest $\Delta \mathrm{T}$ value $\left(305^{\circ} \mathrm{C}\right)$, among the set of glasses analyzed. A glass rod was prepared by melt-quenching, using a $30 \mathrm{~g}$ batch of glass. The batch was melted in a platinum crucible tube, at $1450{ }^{\circ} \mathrm{C}$ for $1 \mathrm{~h}$, under an atmosphere of $\mathrm{N}_{2}$ at a flow rate of $30 \mathrm{~mL} \mathrm{~min}^{-1}$, in an induction furnace.

The cylindrical stainless steel mold was pre-heated at $555^{\circ} \mathrm{C}\left(50{ }^{\circ} \mathrm{C}\right.$ below $\left.\mathrm{T}_{\mathrm{g}}\right)$ for $2 \mathrm{~h}$ before the melt-quenching process, in order to ensure an even temperature. The dimensions of the mold were $10 \mathrm{~cm}$ long and $10 \mathrm{~mm}$ diameter. The rod preform was annealed for $6 \mathrm{~h}$ at 555 ${ }^{\circ} \mathrm{C}$ and cooled at a rate of $0.5^{\circ} \mathrm{C} \mathrm{min}^{-1}$, requiring $17.5 \mathrm{~h}$ to reach room temperature. To minimize the structural stress of the BGB-8Tb preform, a second annealing process was performed under the same conditions used previously. Glass preforms containing high concentrations of RE oxides generally present high structural stress, requiring a long annealing time and a slow cooling rate. After the cooling process, the preform was polished in several steps using $\mathrm{SiC}$ papers (600 to 1200 grit).

In the final step, the preform was mounted into the drawing tower and the fiber drawing process was started at $720{ }^{\circ} \mathrm{C}\left(\mathrm{T}_{\mathrm{g}}+115^{\circ} \mathrm{C}\right)$. During the drawing process, the BGB-8Tb fiber was coated with a low-index UV-cured poly(methyl methacrylate) (PMMA) polymer, in order to protect the magneto-optical fiber and improve its mechanical properties.

Measurements and characterizations. Differential scanning calorimetry (DSC) measurements of the BGB- $x$ Tb glasses were performed using a Netzsch DSC Pegasus 404F3 apparatus. For this, the glass sample $(10 \mathrm{mg})$ was placed in a platinum crucible and heated from 
25 to $1000{ }^{\circ} \mathrm{C}$, at a rate of $10{ }^{\circ} \mathrm{C} \mathrm{min}^{-1}$, under an atmosphere of nitrogen $\left(20 \mathrm{~mL} \mathrm{~min}^{-1}\right)$. The maximum errors were $\pm 2{ }^{\circ} \mathrm{C}$ for $\mathrm{T}_{\mathrm{g}}$ and $\mathrm{T}_{\mathrm{x}}$, and $\pm 4{ }^{\circ} \mathrm{C}$ for $\Delta \mathrm{T}$.

Powder X-ray diffraction measurements were carried out with a Panalytical Aries benchtop diffractometer operating with a $\mathrm{Cu} \mathrm{K} \alpha$ radiation source. Scanning was performed in the $2 \theta$ range from $10^{\circ}$ to $80^{\circ}$, with step size of $0.01^{\circ}$ and step time of $2 \mathrm{~s}$.

Raman spectra were recorded at room temperature, in the frequency range from 100 to $1800 \mathrm{~cm}^{-1}$, using a Renishaw inVia Micro-Raman spectrometer equipped with a $633 \mathrm{~nm}$ laser delivering $17 \mathrm{~mW}$, coupled with a Leica DM2700 microscope.

HRTEM images and SAED patterns for the BGB-18Tb glass were obtained using an FEI Tecnai G2 F20 (200 kV) transmission electron microscope equipped with a field emission gun, coupled with an energy dispersive spectroscopy (EDS) microanalysis system. For the analysis, the BGB-18Tb glass was finely powdered, suspended in ethanol, and deposited onto a copper grid.

Density measurements were performed with a Mettler Toledo Excellence XS densimeter. The measurement precision was $\pm 0.002 \mathrm{~g} \mathrm{~cm}^{-3}$.

Optical absorption and transmission spectra of the BGB- $x$ Tb glasses were obtained using a Varian Cary 500 dual-beam UV-Vis-NIR spectrophotometer, in the ranges from 200 to $800 \mathrm{~nm}$ and from 0.25 to $3 \mu \mathrm{m}$, respectively. Linear refractive indexes for the BGB samples were determined at 532,633, 972, 1038, and $1538 \mathrm{~nm}$ by the prism coupling technique, using a Metricon 2010 M-Lines instrument, with precision of \pm 0.0001 .

Excitation, emission, and photoluminescence decay curves were obtained using a Fluorolog near-infrared photomultiplier tube system (NIR-PMT) (Horiba Jobin Yvon) equipped with a xenon lamp (200-900 nm). The PL measurements were performed with bulk samples, at room temperature.

Faraday rotation measurements. Faraday rotation values of the BGB- $x \mathrm{~Tb}$ glasses were obtained at room temperature, using a neodymium magnet with a total magnetic field $(B)$ of $0.46 \mathrm{~T}$. For the Faraday rotation angle $(\theta)$, a standardized sample length $(l)$ of $1.9 \mathrm{~cm}$ was used. The faces of all the samples were polished to obtain flat surfaces. The Faraday rotation angles were measured at 500, 650, 880, 1030, 1308, and $1550 \mathrm{~nm}$, using a SuperK COMPACT supercontinuum laser (NKT Photonics) with spectral range from 450 to $2400 \mathrm{~nm}$, power of 100 $\mathrm{mW}$, and operating temperature range of $15-30^{\circ} \mathrm{C}$.

The laser beam was focused on the BGB- $x \mathrm{~Tb}$ sample and the polarized light transmitted through the glass was measured using a graduated polarizer. The output beam was detected at 
500, 650, 880, and $1050 \mathrm{~nm}$, using a PM100D Handheld Optical Power and Energy Meter (Thorlabs), and at 1330 and $1550 \mathrm{~nm}$, using a PDA015C InGaAs Fixed Gain Amplified Detector (Thorlabs) connected to a Model $2512100 \mathrm{MHz} 1 \mathrm{GSa} / \mathrm{s}$ Handheld Digital Storage Oscilloscope (BK Precision).

Similarly, Faraday rotation angle measurements for the BGB-8Tb fiber were performed at $500,650,880,1050,1330$, and $1550 \mathrm{~nm}$. The input and output fibers were cleaved using a 24X0-RCL cleaving machine and the optical path length $(l)$ was $2 \mathrm{~cm}$. The fiber was inserted in a holder and a 40x objective lens was used to focus the laser onto the fiber section. The Faraday rotation angles were measured in triplicate, using a polarizer with precision of $\pm 2^{\circ}$. The Verdet constant values $\left(V_{B}, \operatorname{rad~T}^{-1} \mathrm{~m}^{-1}\right)$ were obtained from the Faraday rotation (Equation $5)$.

$$
V_{B}=\frac{\theta}{B . l}
$$

Optical fiber characterization. The cut-back fiber loss method was used to measure the optical attenuation of the BGB-8Tb fiber in the range from 350 to $1750 \mathrm{~nm}$. The attenuation spectra were acquired using an optical spectrum analyzer (OSA) (Model AQ-6315A, Yokogawa) with wavelength resolution of $5 \mathrm{~nm}$. To obtain flat surfaces, the input and output of the BGB-8Tb fiber were cleaved using a 24X0-RCL cleaving machine, after which the fiber was clamped into two SubMiniature version A (SMA) adaptors. For broadband measurement, the input fiber was clamped at the tungsten-halogen lamp housing and the output was connected to an OSA instrument. The cutback measurements were performed from the initial fiber length of $1.92 \mathrm{~m}$ to a final length of $21.8 \mathrm{~cm}$. The output fiber was cut into different lengths using the cleaving machine and the output power was measured for each length, in order to obtain more accurate transmission losses data.

\section{Data availability}

All data regarding the work presented here are available upon reasonable request to the corresponding authors. 


\section{References}

1. Gao, G., Winterstein-Beckmann, A., Surzhenko, O., Dubs, C., Dellith, J., Schmidt, M. A., $\&$ Wondraczek, L. Faraday rotation and photoluminescence in heavily $\mathrm{Tb}^{3+}$-doped $\mathrm{GeO}_{2}-\mathrm{B}_{2} \mathrm{O}_{3}-$ $\mathrm{Al}_{2} \mathrm{O}_{3}-\mathrm{Ga}_{2} \mathrm{O}_{3}$ glasses for fiber-integrated magneto-optics. Sci. Rep 5, 1-6. https://doi.org/10.1038/srep08942 (2015).

2. Qiu, X., Wu, B., Liu, Y., Wen, F. Study on mode coupling characteristics of multimode

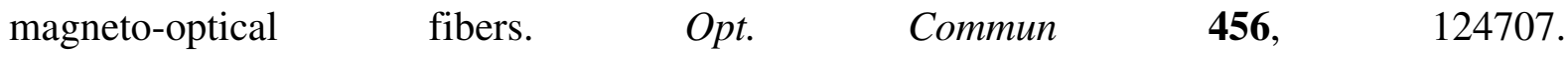
https://doi.org/10.1016/j.optcom.2019.124707 (2020).

3. Valeanu, M., Sofronie, M., Galca, A. C., Tolea, F., Elisa, M., Sava, B., Boroica, L., Kuncser, $\mathrm{V}$. The relationship between magnetism and magneto-optical effects in rare earth doped aluminophosphate glasses. J Phys D Appl Phys 49(7), 075001. https://doi.org/10.1088/00223727/49/7/075001 (2016).

4. Kruk, A., Wajler, A., Mrózek, M., Zych, Ł., Gawlik, W., \& Brylewski, T. Transparent yttrium oxide ceramics as potential optical isolator materials, Opt Appl. 45(4), 585-594. https://doi.org/10.5277/oa150413 (2015).

5. Chen Q., Wang H., Chen Q., Structural and properties of heavy metal oxide Faraday glass for optical current transducer. J. Non-Cryst. Solids 429, 13-19. https://doi.org/10.1016/j.jnoncrysol.2015.08.031 (2015).

6. Babkina, A., Kulpina, E., Sgibnev, Y., Fedorov, Y., Starobor, A., Palashov, O., Nikonorov, N., Ignatiev, A., Zyryanova, K., Oreshkina, K., Zhizhin, E., \& Pudikov, D. Terbium concentration effect on magneto-optical properties of ternary phosphate glass., Opt. Mater 100, 109692. https://doi.org/10.1016/j.optmat.2020.109692 (2020).

7. Mollaee, M., Zhu, X., Jenkins, S., Zong, J., Temyanko, E., Norwood, R., Chavez-Pirson, A., Li, M., Zelmon, D., Peyghambarian, N. Magneto-optical properties of highly $\mathrm{Dy}^{3+}$ doped multicomponent glasses , Opt. Express 28(8), 11789. https://doi.org/10.1364/oe.392008 (2020).

8. Fernandes, R. G., Franco, D. F., Mastelaro, V. R., Cardinal, T., Toulemonde, O., Nalin, M. Thermal and structural modification in transparent and magnetic germanoborate glasses induced by $\mathrm{Gd}_{2} \mathrm{O}_{3}$. Ceram. Int 46, 22079-22089. https://doi.org/10.1016/j.ceramint.2020.05.227 (2020).

9. Yamane, M., Asahara, Y., Cambridge, Univ. Press 1st Ed., 1, 241-263. http://10.1017/S0263034601224148 (2000).

10. Chen, Q. Optical linear \& nonlinearity and Faraday rotation study on $\mathrm{V}_{2} \mathrm{O}_{5}$ nanorod doped glass and glass-ceramic: Impact of optical basicity. J. Alloys Compd. 828, 154448. 
https://doi.org/10.1016/j.jallcom.2020.155490 (2020).

11. Huang, Y., Chen, H., Dong, W., Pang, F., Wen, J., Chen, Z., Wang, T., Fabrication of europium-doped silica optical fiber with high Verdet constant. Opt. Express 24, 18709-18717. https://doi.org/10.1364/oe.24.018709 (2016).

12. Suzuki, F., Sato, F., Oshita, H., Yao, S., Nakatsuka, Y., \& Tanaka, K. Suzuki, F., Sato, F., Oshita, H., Yao, S., Nakatsuka, Y., \& Tanaka, K. Large Faraday effect of borate glasses with high $\mathrm{Tb}^{3+}$ content prepared by containerless processing. Optical Materials 76, 174-177. https://doi.org/10.1016/j.optmat.2017.12.031 (2018).

13. Yin, H., Gao, Y., Gong, Y., Buchanan, R., Song, J., \& Li, M. Effect of $\mathrm{B}_{2} \mathrm{O}_{3}$ Content and Microstructure on Verdet Constant of $\mathrm{Tb}_{2} \mathrm{O}_{3}$-Doped GBSG Magneto-Optical Glass. Ceram. Int 44(9), 10929-10933. https://doi.org/10.1021/acs.jpcc.8b04989 (2018).

14. Linganna, K., Ju, S., Basavapoornima, C., Venkatramu, V., \& Jayasankar, C. K. Development of aluminosilicate glass fiber doped with high $\operatorname{Pr}^{3+}$ concentration for all-optical fiber isolator application. J. Asian Ceram. Soc. 6(1), 82-87. https://doi.org/10.1007/s10854019-01644-y (2018).

15. Guo, Q., Wen, J., Huang, Y., Wang, W., Pang, F., Chen, Z., Luo, Y., Peng, G. D., Wang, T. Magneto-optical properties and measurement of the novel doping silica optical fibers (2018), IMEKO 127, 63-67. https://doi.org/10.1016/j.measurement.2018.05.032 (2018).

16. Ju, S., Kim, J., Linganna, K., Watekar, P. R., Kang, S. G., Kim, B. H., Boo, S., Lee, Y., An, Y. H., Kim, C. J., Han, W. T. Temperature and vibration dependence of the faraday effect of $\mathrm{Gd}_{2} \mathrm{O}_{3}$ NPs-doped alumino-silicate glass optical fiber. Sensors 18(4), 1-13. https://doi.org/10.3390/s18040988 (2018).

17. Sun, L., Jiang, S., Zuegel, JD., Marciante JR. All-fiber optical isolator based on Faraday rotation in highly terbium-doped fiber. Opt Lett 35, 706-708. https://doi.org/10.1364/OL.35.000706 (2010).

18. Bellanger, B., Ledemi, Y., Messaddeq, Y. Fluorophosphate Glasses with High Terbium Content for Magneto-optical Applications. J. Phys. Chem. C 124(9), 5353-5362. https://doi.org/10.1021/acs.jpcc.9b11696 (2020).

19. Jin, W., Ding, J., Guo, L., Gu, Q., Li, C., Su, L., Wu, A., Zeng, F., Growth and performance research of $\mathrm{Tb}_{3} \mathrm{Ga}_{5} \mathrm{O}_{12}$ magneto-optical crystal. J. Cryst. Growth 484, 17-20. https://doi.org/10.1016/j.jcrysgro.2017.12.024 (2018).

20. Franco, D. F., Fernandes, R., Felix, J. F., Mastelaro, V. R., Eckert, H., Afonso, C. R. M., Messaddeq, Y., Messaddeq, S. H., Morency, S., Nalin, M. Fundamental studies of magnetooptical borogermanate glasses and derived optical fibers containing $\mathrm{Tb}^{3+}$. J. Mater. Res. 
Technol 11, 312-327. https://doi.org/10.1016/j.jmrt.2021.01.010 (2021).

21. Guo, H., Wang, Y., Gong, Y., Yin, H., Mo, Z., Tang, Y., \& Chi, L. Optical band gap and photoluminescence in heavily $\mathrm{Tb}^{3+}$ doped $\mathrm{GeO}_{2}-\mathrm{B}_{2} \mathrm{O}_{3}-\mathrm{SiO}_{2}-\mathrm{Ga}_{2} \mathrm{O}_{3}$ magneto-optical glasses. $J$. Alloys Compd. 686, 635-640. https://doi.org/10.1016/j.jallcom.2016.06.074 (2016).

22. Savinkov, V. I., Sigaev, V. N., Golubev, N. V., Sarkisov, P. D., Masalov, A. V., Sergeev, A. P. Borogermanate glasses with a high terbium oxide content. J. Non-Cryst. Solids 356 3334, 1655-1659. https://doi.org/10.1016/j.jnoncrysol.2010.06.011 (2010).

23. Liu, Z., Chen, Z., Chen, N., Huang, Y., Liu, S., Shang, Y., Wang, T., Study of the Verdet constant of the holmium-doped silica fiber. OSA Continuum 3, 1096-1104. https://doi.org/10.1364/OSAC.390111 (2020).

24. Sun, L., Jiang, S., Marciante JR. Compact all-fiber optical Faraday components using 65wt\%-terbium-doped fiber with a record Verdet constant of -32 rad/(T.m). Opt. Express 18, 12191-12196. https://doi.org/10.1364/oe.18.012191 (2010).

25. Franco, D. F., Fernandes, R. G., Santagneli, S. H., Oliveira, M. De, Eckert, H., Nalin, M. (2020). Structural Study of the Germanium - Aluminum - Borate Glasses by Solid State NMR and Raman Spectroscopies. J. Phys. Chem. C 124, 44, 24460-24469. https://doi.org/10.1021/acs.jpcc.0c07810 (2020).

26. Duffy, J. A. A review of optical basicity and its applications to oxidic systems. Geochim. Cosmochim. Acta 57(16), 3961-3970. https://doi.org/10.1016/0016-7037(93)90346-X (1993). 27. Duffy, J. A. Optical basicity: A practical acid-base theory for oxides and oxyanions. $J$. Chem. Educ. 73(12), 1138-1142. https://doi.org/10.1021/ed073p1138 (1996).

28. Liu, S., Zhao, G., Ruan, W., Yao, Z., Xie, T., Jin, J., Ying, H., Wang, J., \& Han, G. Reduction of $\mathrm{Eu}^{3+}$ to $\mathrm{Eu}^{2+}$ in aluminoborosilicate glasses prepared in air. J. Am. Ceram. 91(8), 2740-2742. https://doi.org/10.1111/j.1551-2916.2008.02496.x (2008).

29. Sontakke, A. D., Annapurna, K. Study on $\mathrm{Tb}^{3+}$ - containing high silica and low silica calcium aluminate glasses: Impact of optical basicity. Spectrochim. Acta A 94, 180-185. https://doi.org/10.1016/j.saa.2012.03.052 (2012).

30. Henderson, G. S., Neuville, D. R., Cochain, B., Cormier, L., The structure of $\mathrm{GeO}_{2}-\mathrm{SiO}_{2}$ glasses and melts: A Raman spectroscopy study. J. Non-Cryst. Solids 355, 468-474. https://doi.org/10.1016/j.jnoncrysol.2009.01.024 (2009).

31. Mansour, E. Raman spectra and density of $\mathrm{Li}_{2} \mathrm{O}_{-}-\mathrm{B}_{2} \mathrm{O}_{3}-\mathrm{GeO}_{2}$ glasses with high $\mathrm{Li}_{2} \mathrm{O}$ content. Physica B Condens. Matter 405, 281-286. https://doi.org/10.1016/j.physb.2009.08.074 (2010). 32. Micoulaut, M., Cormier, L., Henderson, G. S. J. Phys. Condens. Matter 18, R753. https://doi.org/10.1088/0953-8984/18/45/R01 (2006). 
33. Kamitsos, E. I., Yiannopoulos, Y. D., Karakassides, M. A., Chryssikos, G. D., Jain, H. Raman and infrared structural investigation of $\mathrm{xRb}_{2} \mathrm{O} \cdot(1-\mathrm{x}) \mathrm{GeO}_{2}$ glasses J. Phys. Chem. 100, 11755-11765. https://doi.org/10.1021/jp960434 (1996).

34. Koroleva, O. N., Shtenberg, M. V., Ivanova, T. N. The structure of potassium germanate glasses as revealed by Raman and IR spectroscopy. J. Non-Cryst. Solids 510, 143-150. https:// 10.1016/j.jnoncrysol.2019.01.017 (2019).

35. Koroleva, O. N., Osipov A. A. In situ Raman spectroscopy of $\mathrm{K}_{2} \mathrm{O}-\mathrm{GeO}_{2}$ melts. J. NonCryst. Solids 531, 1-6. https://doi.org/10.1016/j.jnoncrysol.2019.119850 (2020).

36. Koroleva, O. N., Shtenberg, M. V., Zainullina, R. T., Lebedeva, S. M. Vibrational spectroscopy and density of $\mathrm{K}_{2} \mathrm{O}-\mathrm{B}_{2} \mathrm{O}_{3}-\mathrm{GeO}_{2}$ glasses with variable $\mathrm{B} / \mathrm{Ge}$ ratio. Phys. Chem. Chem. Phys. 21, 12676-12684. https://doi.org/10.1039/c9cp01374a (2019).

37. Nakamoto, K. Infrared and Raman Spectra of Inorganic and Coordination Compounds (Part A). Wiley, 6, 142. https://doi.org/10.1002/9780470405840 (1978).

38. Verweij, H., Buster, J. H. J. M., The structure of lithium, sodium and potassium germanate glasses, studied by Raman scattering. J. Non-Cryst. Solids 34, 81-99. https://doi.org/10.1016/0022-3093(79)90008-5 (1979).

39. Jaba, N., Mermet, A., Duval, E., Champagnon, B. (2005). Raman spectroscopy studies of $\mathrm{Er}^{3+}$-doped zinc tellurite glasses. J. Non-Cryst. Solids 351(10-11), 833-837. https://doi.org/10.1016/j.jnoncrysol.2005.02.003 (2005).

40. Wan, X., Zhong, Q., Tie, S. L., Shen, J. Y. Synthesis and luminescence properties of $\mathrm{Tb}^{3+}$ activated $\mathrm{CaO}-\mathrm{Al}_{2} \mathrm{O}_{3}-\mathrm{B}_{2} \mathrm{O}_{3}$ glass. Optoelectron. Adv. Mater. 5(5), 538-544 (2011) (2011).

41. Sontakke, A. D., Biswas, K., Annapurna, K. J. Lumin. 129 (11), 1347-1355. https://doi.org/10.1016/j.jlumin.2009.06.027 (2009).

42. Ghosh G. Sellmeier coefficients and dispersion of thermo-optic coefficients for some optical glasses. Appl. Opt. 36, 1540-1546. https://doi.org/10.1364/AO.36.001540 (1997).

43. Juárez-Batalla. J., Meza-Rocha A. N., Muñoz G. H., Camarillo I., Caldiño U. Opt. Mater. 58, 406-411. https://doi.org/10.1016/j.optmat.2016.06.022 (2016).

44. Sharma, S., De, M., Jana, S. Terbium doped sodium phosphate glass: A strong green emitting glass. Optik, 154, 576-580. https://doi.org/10.1016/j.ijleo.2017.10.068 (2018).

45. Zur, L., Sołtys, M., Pisarska, J., Pisarski, W. A. Absorption and luminescence properties of terbium ions in heavy metal glasses., J. Alloys Compd. 578, 512-516. https://doi.org/10.1016/j.jallcom.2013.07.021 (2013).

46. Chen, Q., Chen, Q., Wang, H., Wang, G., Yin, S. Magneto optical properties of rare earth $\mathrm{Tb}_{2} \mathrm{O}_{3}$ doped $\mathrm{PbO}_{-} \mathrm{Bi}_{2} \mathrm{O}_{3}-\mathrm{B}_{2} \mathrm{O}_{3}$ glass. J. Non-Cryst. Solids 470, 99-107. 
https://doi.org/10.1016/j.bsecv.2016.07.002 (2017).

47. Panmand, R. P., Tekale, S. P., Daware, K. D., Gosavi, S. W., Jha, A., Kale, B. B. Characterisation of spectroscopic and magneto-optical faraday rotation in $\mathrm{Mn}^{2+}$ - doped $\mathrm{CdS}$ quantum dots in a silicate glass. J. Alloys Compd., 817, 152696. https://doi.org/10.1016/j.jallcom.2019.152696 (2020).

48. Dongbing, H., Chunlei, Y., Jimeng, C., Shunguang, L., Lili, H. Energy transfer between $\mathrm{Gd}^{3+}$ and $\mathrm{Tb}^{3+}$ in phosphate glass. J. Rare Earth 29, 48-51. https://doi.org/10.1016/S10020721(10)60392-4 (2011).

49. Letellier, V., Seignac, A., Le Floch, A., Matecki, M. Magneto-optical properties of heavily rare-earth doped non-crystalline fluorophosphates. J. Non-Cryst. Solids 111, 55-62. https://doi.org/10.1016/0022-3093(89)90423-7 (1989).

50. Qiu, J., Tanaka, K., Sugimoto, N., Hirao, K. Faraday effect in $\mathrm{Tb}^{3+}$-containing borate, fluoride and fluorophosphate glasses. J. Non-Cryst. Solids 213-214, 193-198. https://doi.org/10.1016/S0022-3093(97)00101-4 (1997).

51. Berger, S. B., Rubinstein, C. B., Kurkjian, C. R.,Treptow, A.W. Faraday rotation of rareearth (III) phosphate glasses. Phys. Rev. 133, A723-A727. https://doi.org/10.1103/PhysRev.133.A723 (1964).

52. Petrovskii, G. T., Edelman, I. S., Zarubina, T. V., Malakhovskii, A. V., Zabluda, V. N., Ivanov, M. Y. Faraday effect and spectral properties of high-concentrated rare earth oxide glasses in visible and near UV region. J. Non-Cryst. Solids 130, 35-40. https://doi.org/10.1016/0022-3093(91)90153-W (1991).

53. Yuan, S. H., Shu, X. Z. A new Faraday rotation glass with a large Verdet constant. J. Appl. Phys. 75, 6375-6377. https://doi.org/10.1063/1.355354 (1994).

54. Kumari, S., Chakraborty, S. Study of different magneto-optic materials for current sensing applications. J. Sens. Sens. Syst. 7, 421-431. https://doi.org/10.5194/jsss-7-421-2018 (2018). 55. Ruan Y., Jarvis, R. A., Rode A. V., Madden S, Luther-Davies B. Wavelength dispersion of Verdet constants in chalcogenide glasses for magneto-optical waveguide devices. Opt. Commun 252, 39-45. https://doi.org/10.1016/j.optcom.2005.03.037 (2005).

56. Kanamori, H., Yokota, H., Tanaka, G., Watanabe, M., Ishiguro, Y., Yoshida, I., Kakii, T., Asano, Y., Tanaka, Transmission Characteristics and Reliability of Pure- Silica-Core SingleMode Fibers. S. J. Light. Technol L(8), 1144-1150. http://10.1109/JLT.1986.1074837 (1986). 57. Smith, A. M. Faraday effect in single-mode optical fiber using an injection laser light source. Electron. Lett. 16, 206-208. http://10.1049/el:19800148 (1980).

58. Harrison, M. T., Kershaw, S. V, Weller, H. Colloidal nanocrystals for telecommunications. 
Complete coverage of the low-loss fiber windows by mercury telluride quantum dots. Pure Appl. Chem. 72, 295-307. https://doi.org/10.1351/pac200072010295 (2014).

\section{Acknowledgments}

The authors are grateful to the São Paulo State Research Foundation (FAPESP, grants 2016/16900-9, 2018/19272-4, and 2013/07793-6) for financial support, and to the Centre d'optique, Photonique et laser (COPL) at Université Laval (Canada).

\section{Author Contributions}

D.F.F. wrote the paper and synthesized the glass samples and the optical fiber and carried out the DSC, XRD, Raman, UV-Vis, M-Lines, Photoluminescence, Attenuation and Magneto-optical measurements. Y.L. participated in the synthesis of the glass samples and the PL measurements. W.C. participated in the SEM and magneto-optical measurements. S.M. was responsible for the fiber drawing process. C.R.M.A. has carried out the morphological characterization (HRTEM). S.M. participated in the review of the manuscript and contributed to the discussion of data. Y.M. supervised the preparation and characterization of the glass samples and optical fiber and contributed to the discussion of data. M.N. is the supervisor of the project, participated in the writing of the manuscript and contributed to the discussion of data. All authors reviewed the manuscript.

\section{Competing interests}

The authors declare no competing interests.

\section{Additional information}

Correspondence and requests for materials should be addressed to M.N. and D.F.F. 
Figures

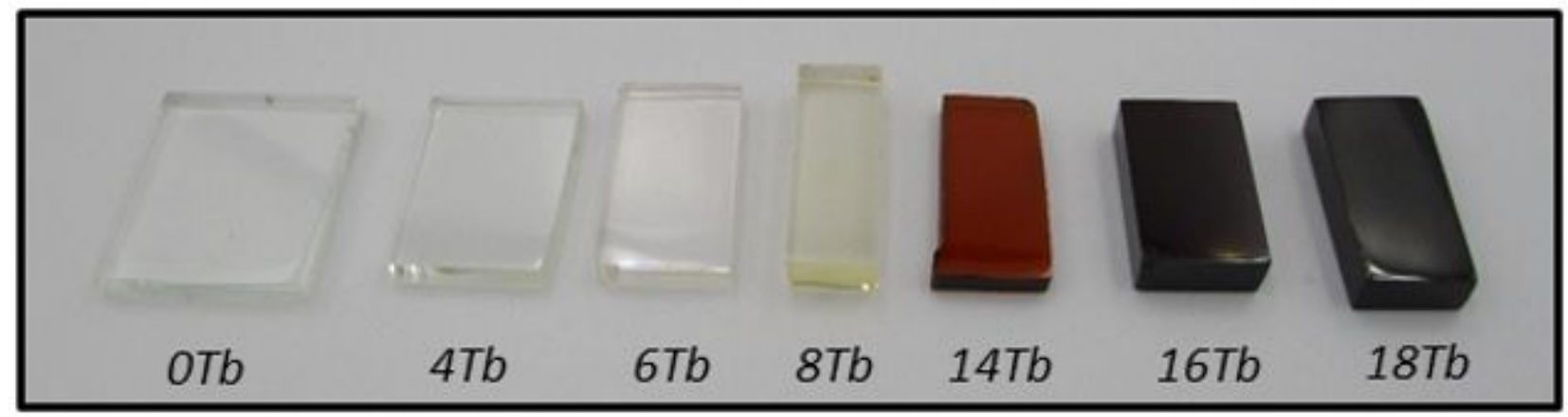

Figure 1

Photograph of BGB-xTb glasses with different Tb407 contents.
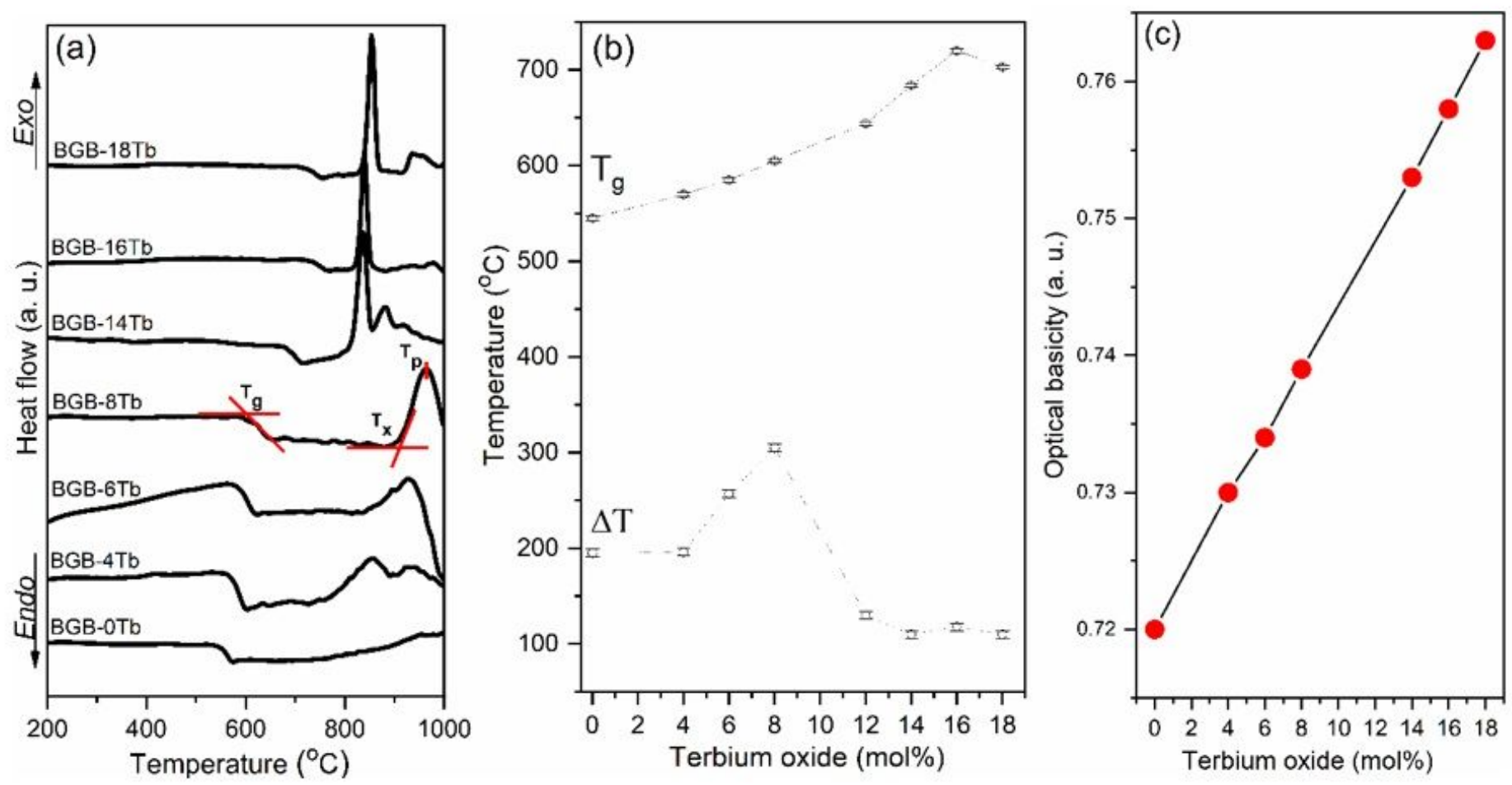

Figure 2

(a) DSC curves, (b) $\mathrm{Tg}$ and $\Delta \mathrm{T}$, and (c) optical basicity, as a function of Tb407 concentration. The lines in (b) and (c) are just guides for the eyes. 


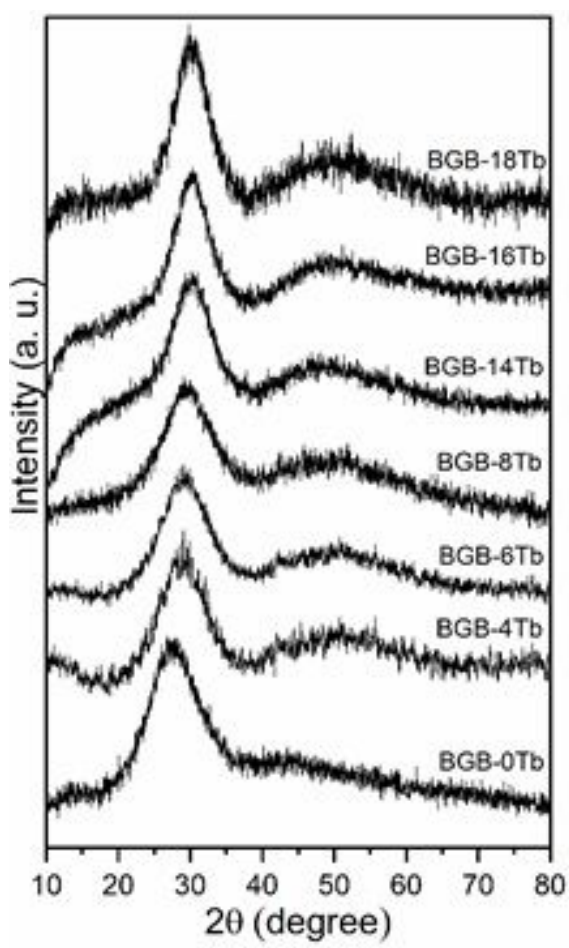

Figure 3

XRD patterns for the BGB-xTb glasses.
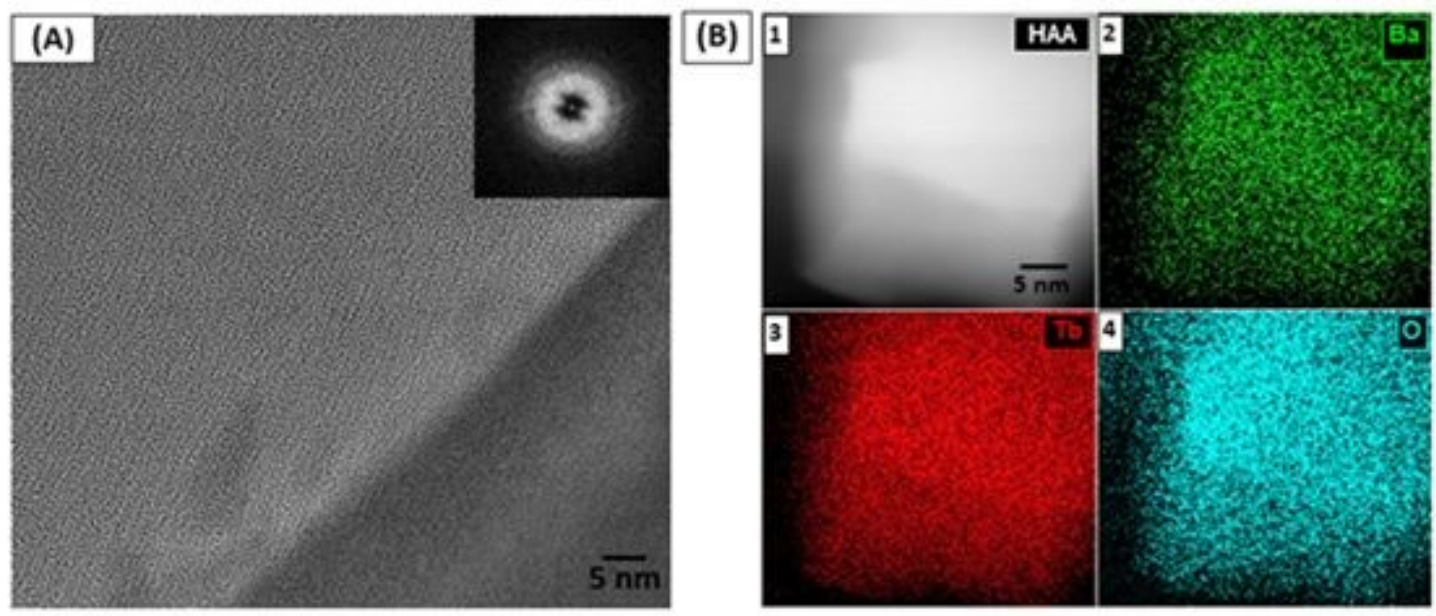

\section{Figure 4}

(A) HRTEM micrograph of BGB-18Tb (the inset shows the fast Fourier transform (FFT)). (B) HAADF mode (Z-contrast) image of the analyzed area (1) and elemental EDS mapping for Ba-K (2), Tb-L (3), and O-K (4). 


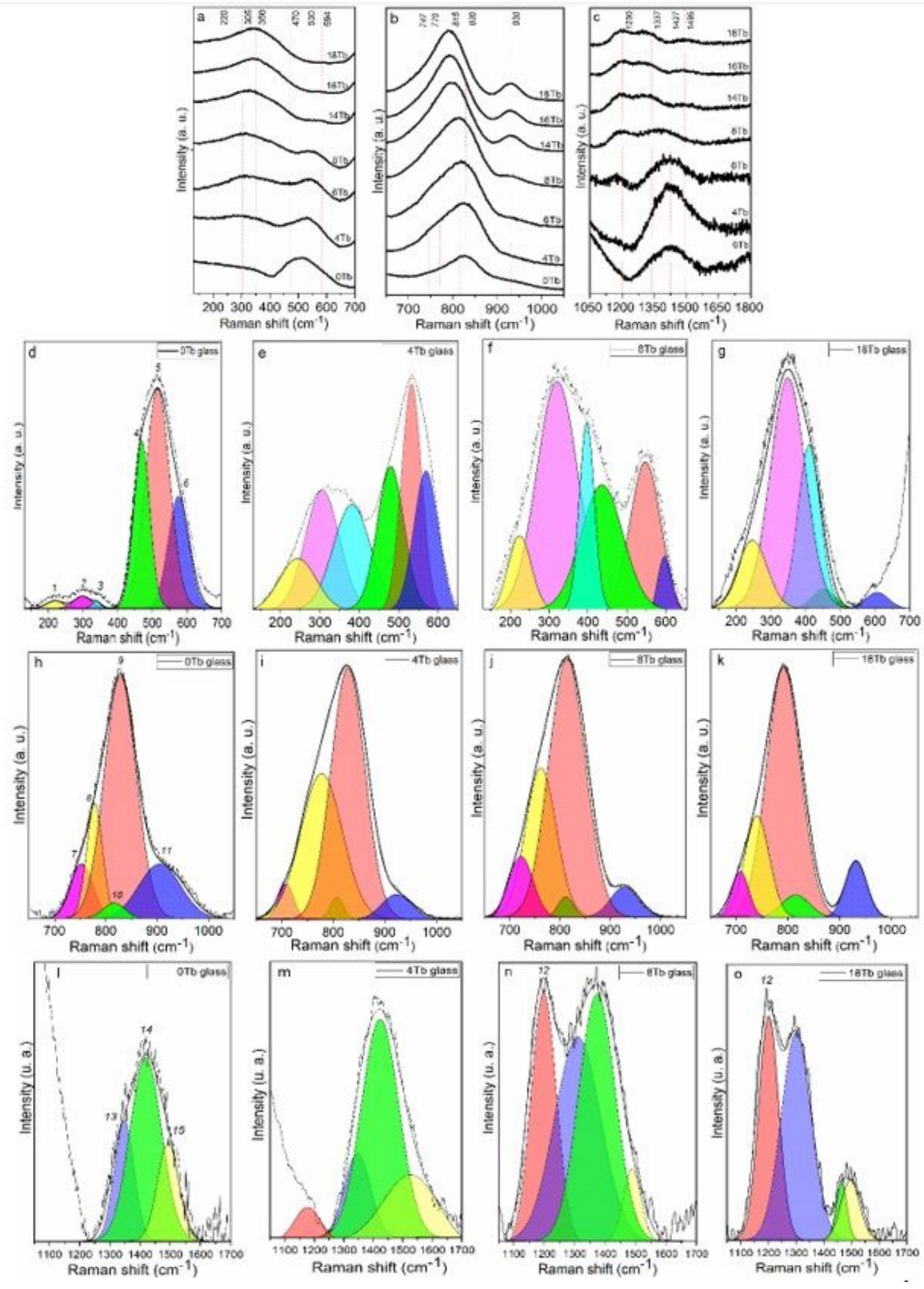

Figure 5

Normalized Raman spectra for the BGB-xTb glasses in (a) low ( 130-700 cm-1), (b) medium ( 650-1050 $\mathrm{cm}-1$ ), and (c) high (1050-1700 cm-1) frequency regions. Deconvolution of the Raman spectra for the 0,4 , 8 , and 18Tb glasses in the low (d-g), medium ( $\mathrm{h}-\mathrm{k})$, and high (l-o) frequency regions. 

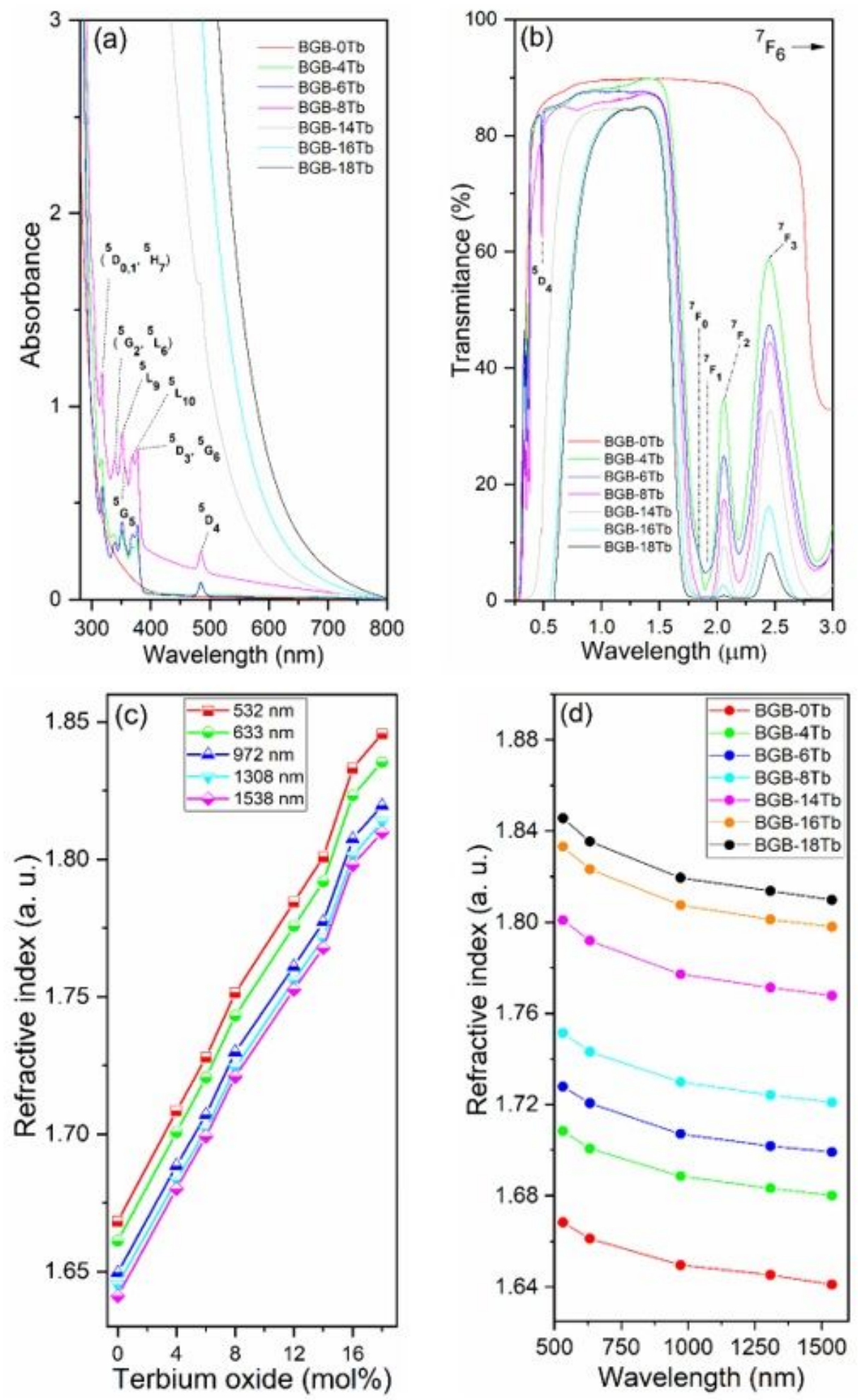

\section{Figure 6}

(a) UV-Vis-NIR optical absorption, (b) transmission spectra, (c) refractive indices as a function of Tb407 content, at different wavelengths, and (d) refractive indices for BGB-xTb glasses $(0 \leq x \leq 18)$, as a function of wavelength. 

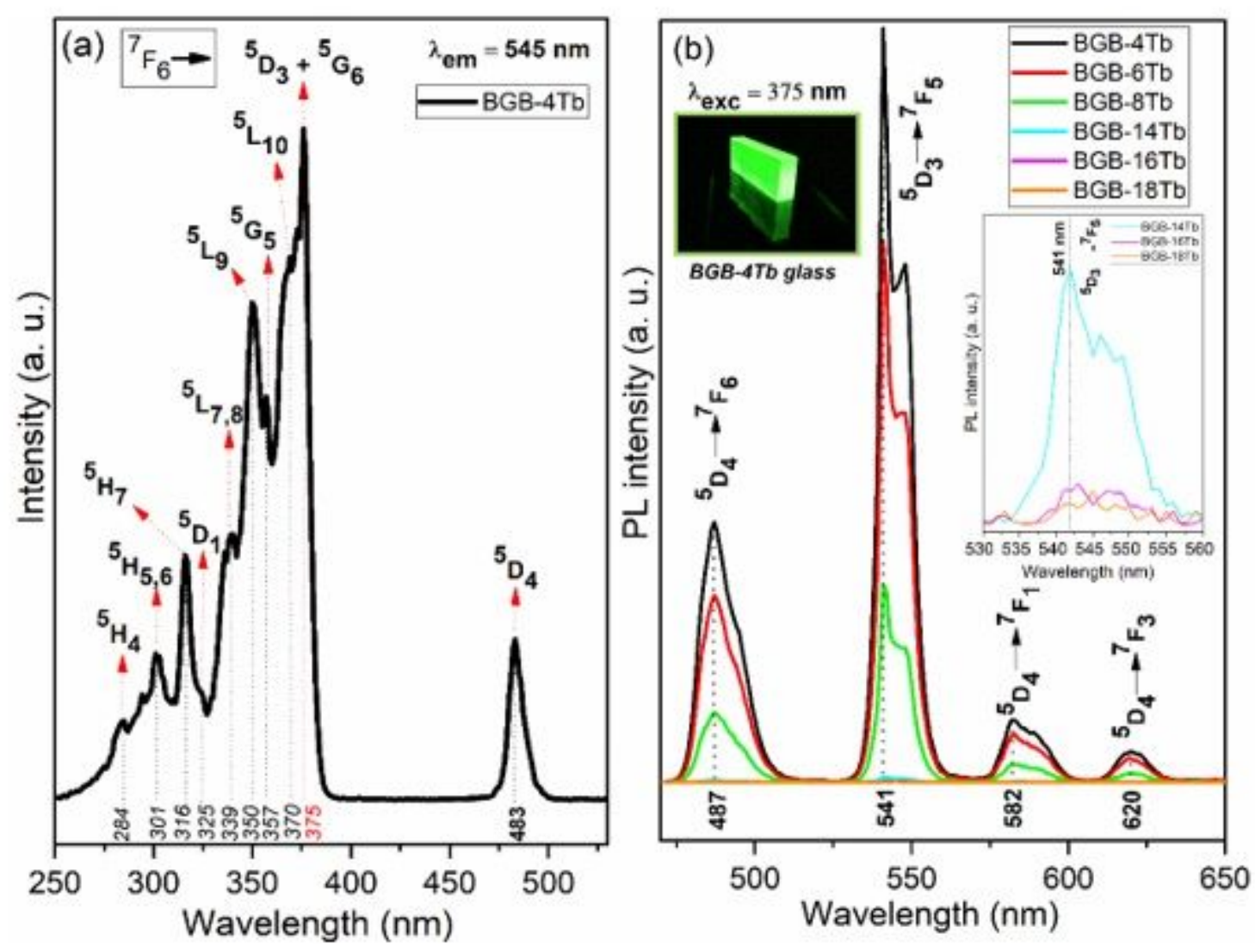

Figure 7

(a) PLE spectrum of the BGB-4Tb glass and (b) PL spectra of the BGB-xTb glasses at room temperature. Inset photograph: BGB-4Tb sample under excitation at $375 \mathrm{~nm}$. Inset: PL spectra of the BGB-xTb glasses $(x=14,16$, and $18 \mathrm{~mol} \%$ Tb407) in the region from 530 to $560 \mathrm{~nm}$. 


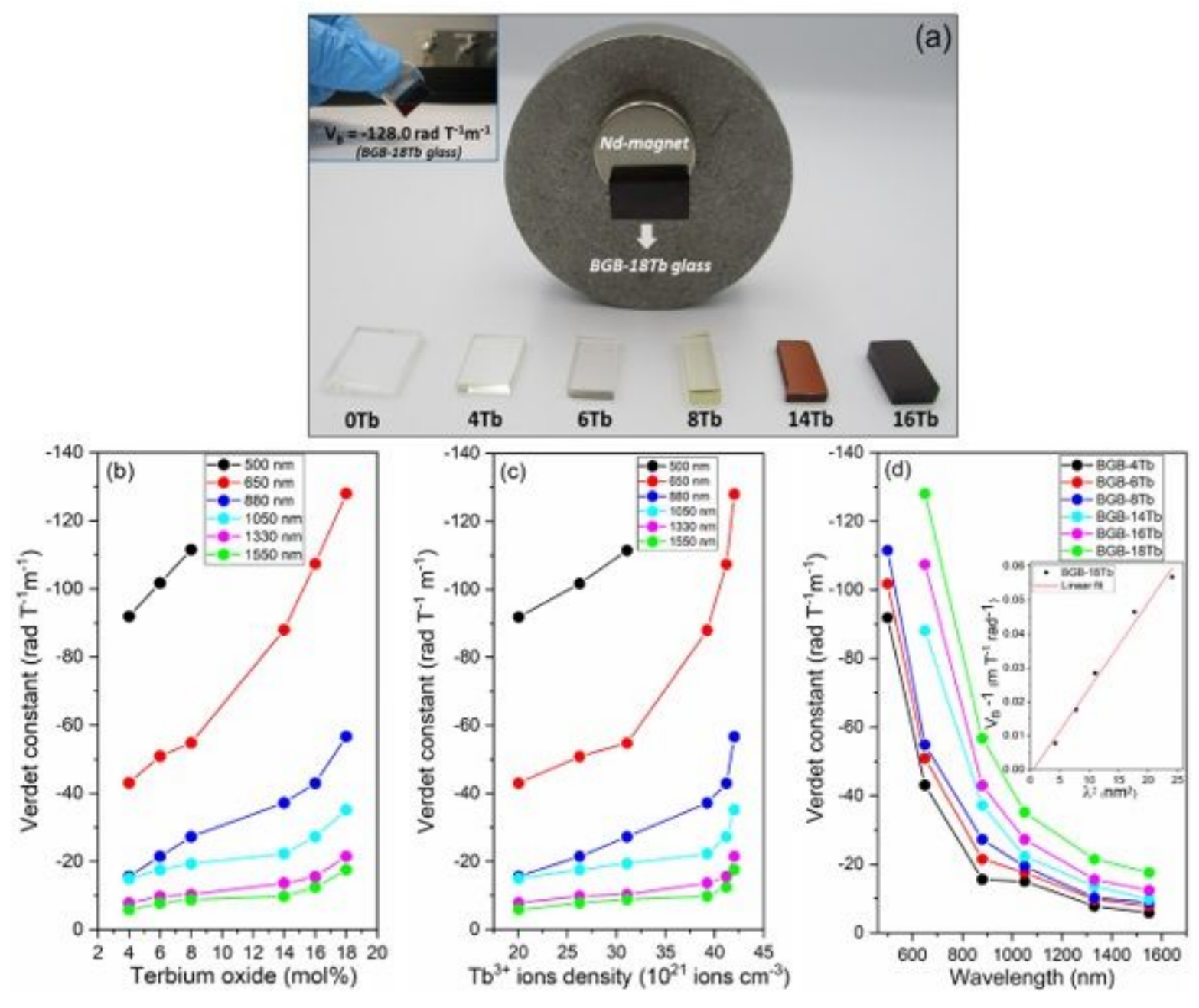

\section{Figure 8}

(a) Photographs of the BGB-xTb glasses and the magnetic attraction of the BGB-18Tb glass using a commercial neodymium magnet. Plots of VB as a function of (b) Tb407 content (mol\%), (c) Tb3+ ions density ( $\mathrm{g} \mathrm{cm}-3)$, and (d) wavelength. 


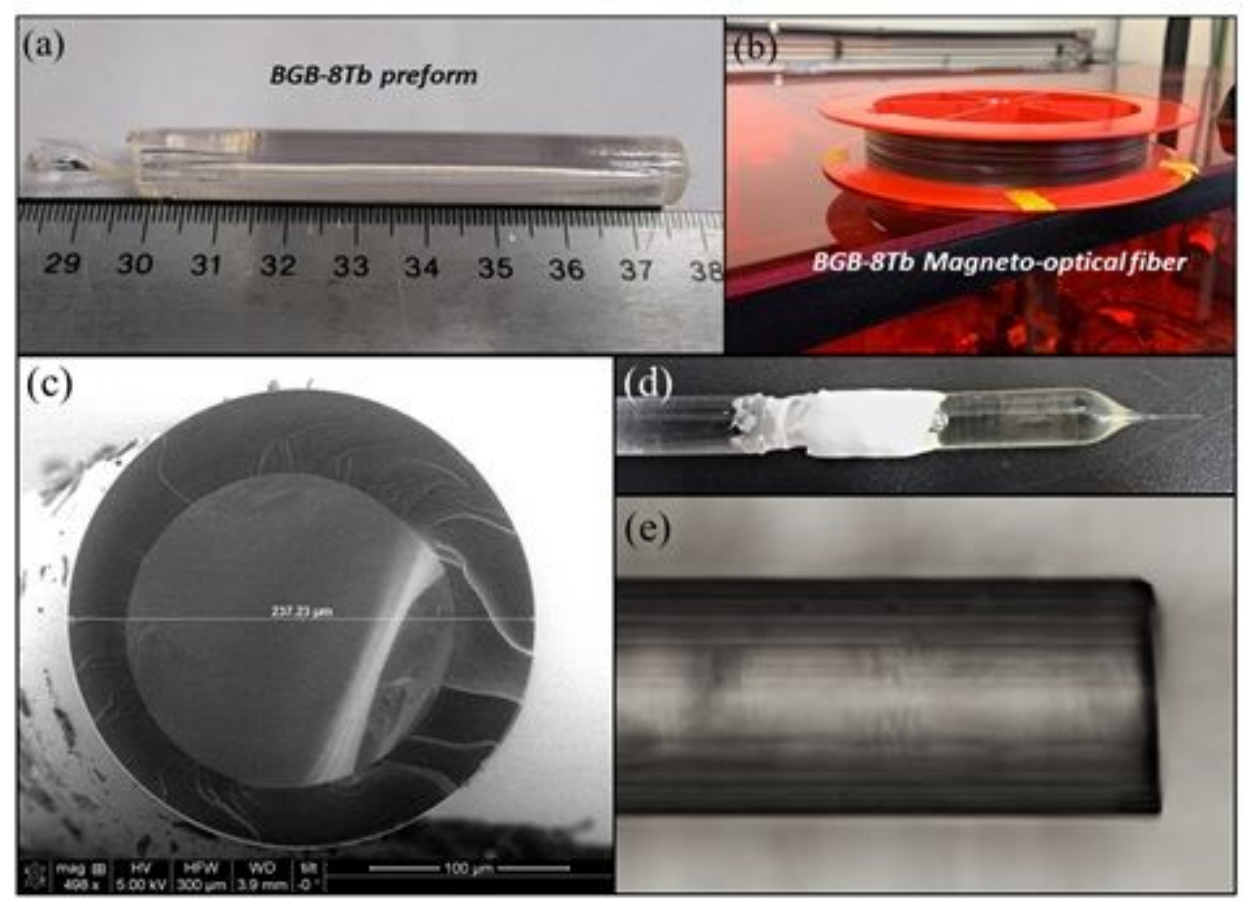

Figure 9

(a) Glass preform, (b) MO fiber based on the BGB-8Tb composition, (c) SEM cross-section image of the BGB-8Tb fiber, (d) glass preform after the drawing process, and (e) optical microscopy image of the surface of the fiber.
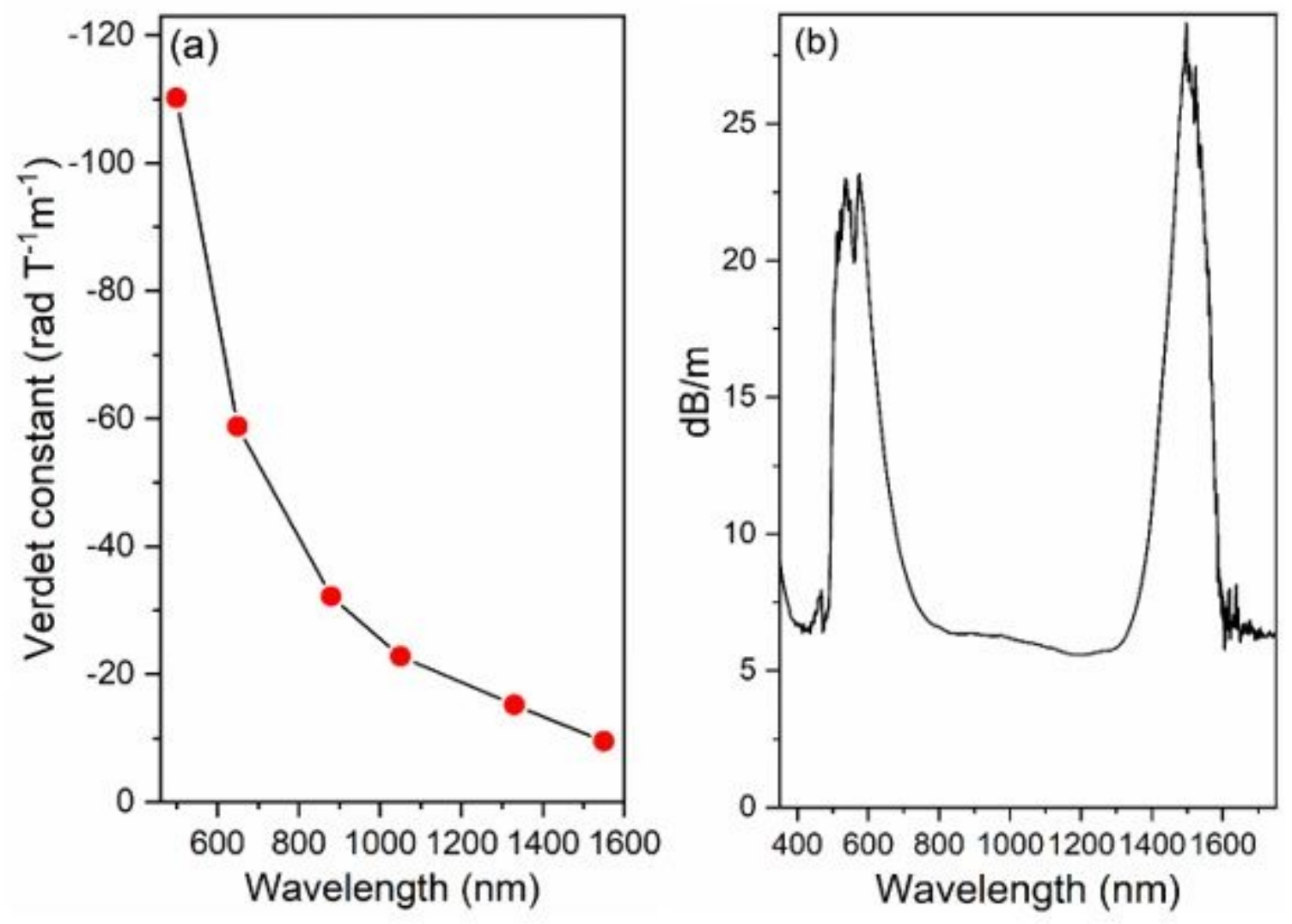
Figure 10

(a) Variation of the Verdet constant as a function of wavelength and (b) attenuation spectrum of the BGB-8Tb fiber determined using the cut-back method, with a final length of $0.21 \mathrm{~cm}$.

\section{Supplementary Files}

This is a list of supplementary files associated with this preprint. Click to download.

- Table1.docx

- Table2.docx

- Supplementaryinformation.pdf

- Supplementaryinformation.pdf 